This item was submitted to Loughborough's Research Repository by the author.

Items in Figshare are protected by copyright, with all rights reserved, unless otherwise indicated.

\title{
Consumer expectations and perception of clothing comfort in sports and exercise garments
}

\section{PLEASE CITE THE PUBLISHED VERSION}

https://doi.org/10.1108/RJTA-01-2021-0015

\section{PUBLISHER}

Emerald

VERSION

AM (Accepted Manuscript)

\section{PUBLISHER STATEMENT}

This paper was accepted for publication in the journal Research Journal of Textile and Apparel and the definitive published version is available at https://doi.org/10.1108/RJTA-01-2021-0015.

\section{LICENCE}

CC BY-NC 4.0

\section{REPOSITORY RECORD}

Wilfling, Julia, George Havenith, Margherita Raccuglia, and Simon Hodder. 2021. "Consumer Expectations and Perception of Clothing Comfort in Sports and Exercise Garments". Loughborough University. https://hdl.handle.net/2134/14906460.v1. 


\section{Consumer expectations and perception of clothing comfort in sports and exercise garments}

\begin{tabular}{|r|l|}
\hline Journal: & Research Journal of Textile and Apparel \\
\hline Manuscript ID & RJTA-01-2021-0015.R5 \\
\hline Manuscript Type: & Original Manuscripts \\
\hline Keyword: & $\begin{array}{l}\text { Clothing comfort, Sports garments, Purchase behaviour, Material } \\
\text { perception, Fibre preferences, Haptics }\end{array}$ \\
\hline \multicolumn{2}{|l}{} \\
\hline
\end{tabular}

\section{SCHOLARONE \\ Manuscripts}




\section{TITLE}

2 Consumer expectations and perception of clothing comfort in sports and exercise garments 


\section{ABSTRACT}

4 Purpose

5 Sports garments play an important role in the well-being of an athlete by protecting the wearer

6 from changing environmental conditions and providing a comfortable feel. Clothing

7 requirements have changed in recent years and demand for apparel with a higher comfort

8 performance have been rising. Hence, the purpose of this study was to explore consumers'

9 expectations and perception of comfort, and to examine how different textiles are perceived by consumers to provide useful knowledge that allows to engineer comfort into fabrics and sports

11 garments.

\section{Design/methodology/approach}

This online survey comprised 292 respondents, classified by sex, age, nationality, and physical activity. The respondents were asked a total of 18 questions through the Bristol Online Survey (BOS) tool to explore expectation, perception and preference of clothing comfort, specifically of sportswear.

\section{Findings}

Fit and comfort are closely linked together, both forming part of the clothing comfort concept. When purchasing garments online, the haptics of fabrics was identified as a crucial missing parameter. However, priorities of attributes within the concept varied according to the person's sex and nationality. Females put more emphasis on garment fit and showed higher need for tactile input, whereas males prioritised physiological comfort descriptors, i.e., properties which facilitate thermoregulation. Furthermore, there is an increased importance of physiological comfort parameters for people exercising for 10 or more hours per week. Finally, it was possible to identify common associations and preferences for textile materials (cotton, polyester, cotton/polyester blend and wool). However, consideration should be taken concerning sex and nationality. 


\section{Originality/value}

29 Sex and nationality are parameters modulating the clothing comfort concept and the 30 conceptualized feel of materials. Therefore, sex and nationality of the end-consumer should be

31 considered during the development phase of sports garments, and particular attention should be 32 given to the targeted market in which these will be sold.

33 KEY WORDS Clothing comfort, Sports garments, Purchase behaviour, Material perception,

34 Fibre preferences, Haptics

35 PAPER TYPE Research paper 


\section{INTRODUCTION}

The apparel industry faces challenges in satisfying consumers' need due to the change of priorities in the previous decades. During the 80 s and 90 s, consumers tended to buy fashionable clothing, whereas today, consumers are generally more value-orientated (Freire Castelo and de Oliveira Cabral, 2018). Understanding consumers' perceptions of apparel's quality is essential for providing satisfaction, which could lead to a potential competitive advantage, larger market share and higher revenue for apparel companies. In this regard, one clothing aspect that has to be studied and quantified is comfort. Human's perception of clothing comfort is made when sensory information is received, processed and then compared to past sensory experiences, ultimately representing people's expectations (Rahman, 2011; Freire Castelo and de Oliveira Cabral, 2018). These perceptions lead to the formulation of different clothing attributes, which have different importance for the consumers, and affect purchase decisions. Therefore, having a good understanding of these attributes can help in the product development phase and marketing strategies (Zhang et al., 2002).

\section{Literature review}

Past studies have focused on the evaluation of determinant attributes in the perception of apparel products. In a study by Zhang et al. (2002), it was found that fit, comfort, colour and workmanship were the most important attributes during the purchase decision of casual wear, and that perceptions were affected by geographic and demographic factors. The geographic location was found to impact attributes such as style, colour and brand; for instance, consumers in northern cities of China were relatively less concerned with colour, whereas consumers in Shanghai paid more attention to colour as well as brand name. Differences are difficult to pinpoint, however these can be traced back to tradition and culture. Furthermore, regarding sex, females place more emphasis on fit, comfort, style, colour, and easy care. 
61 Workman and Cho (2013) also indicated that individual preferences are affected by the culture

62 in which a person is exposed to growing up, as well as individual differences such as sex.

63 Additionally, females showed greater preferences for in-store shopping channels than men.

64 Many studies categorised attributes determining consumers' quality perceptions into two

general types: extrinsic and intrinsic cues (Hatch and Roberts, 1985). Intrinsic cues are inherent to the physical composition and cannot be modified without changing the overall product: fibre content, fabric structure, garment construction, quality, style, comfort, and fit. Extrinsic attributes are product related, however, are not part of the physical product. Examples for extrinsic cues are price, brand label, store, and country of origin (Hatch and Roberts, 1985; Swinker and Hines, 2006; Rahman, 2011; Freire Castelo and de Oliveira Cabral, 2018). In the perception of quality across a wide range of products intrinsic cues are considered to be more important than extrinsic ones (Fiore and Damhorst, 1992). This is consistent with findings by Rahman (2011), where intrinsic factors regarding denim products were found to play a more significant role than extrinsic factors.

Comfort in general is of multifactorial nature; in sports garments in particular it influences the overall performance and utility of the garment. A subdivision of three related major groups can be performed: psychological/ergonomic, physical (sensorial/tactile) and physiological comfort (Kamalha et al., 2013). The psychological/ergonomic comfort includes personal aspects such as personality and cultural background, as well as style, aesthetics, fashion, design, colour, fit, and freedom of movement (Bartels, 2005). The physical (sensorial/tactile) comfort refers to the skin-clothing interaction, which triggers various sensory receptors leading to a rise in psychophysical perception. Sensations felt can be tactile (smoothness, roughness, softness, stiffness, scratchiness), thermal (warmth, coolness, breathability), moisture (wetness, stickiness) and pressure sensations (lightweight, heaviness) (Bartels, 2005; Bishop, 1996; Das and Alagirusamy, 2010). Lastly, the physiological comfort refers to body thermoregulation ( $\mathrm{Li}$, 
2005). Rahman's (2011) interpretation of comfort in apparel products involves thermal effects of a garment (warmth, breathability), sensory characteristics (tactile feeling), and mobility (ease of movement). In a more recent study (McCann, 2015), comfort is defined as a combination of appropriate shape and fit, including freedom of movement, thermal regulation via moisture wicking and quick drying properties, as well as lightweight, protection and durability. These factors contributed to the overall 'feel good' factor for the wearer.

When purchasing a sports garment in a shop, direct involvement such as touching, feeling or trying-on the garment is a natural tendency before making a final purchase decision (Rahman, 2011). In-store shopping is still leading over online, however, online purchases have been catching up (Mintel, 2018) especially during the COVID-19 lockdown periods (March/April, October 2020, January 2021). Nike expects a permanent shift to online sales. The US company recorded a digital sales increase of $82 \%$ during the June to August quarter in 2020 (BBC, 2020). Similar to Nike, Adidas' online sales surge by $93 \%$ in the second quarter and $51 \%$ in the third (Meyers, 2020). Apparel companies have had to adapt to changing consumer behaviour during the pandemic by focussing on investments in online direct-to-consumer sales. It is therefore important to investigate people's purchase behaviour to be able to prioritise resources across different channels (e-commerce, physical stores). Regarding e-commerce, a big limiting factor could be represented by the difficulty to feel the garment by hand, especially if haptic response plays a major role in the purchase decision. In a study by Hines \& O’Neal (1995) consumers evaluated quality using attributes that they associated with social, psychological, economic, physiological, and aesthetic characteristics. When evaluating garment quality, fabric material was the only attribute identified by most of the participants. According to the study, if fabric does not meet the requirements and expectations, all other factors like aesthetic, economic/performance, physiological and social/psychological may become unimportant since fabric is an integral part of clothing. Fabric was perceived to have a noticeable effect on the 
111 overall appearance and performance of the garment. This is in accordance with Fiore \&

112 Damhorst (1992) who also stated that fabric is the best predictor of perceived quality of apparel.

113 Product information labels of sports garments are usually stating fibre content and finish, which

114 is helpful in the way of identifying the product composition; however, the consumer must be

115 knowledgeable about which properties are associated with each product component (Hatch and

116 Roberts, 1985). How are materials perceived in consumers' minds? Wool for instance traps air

117 and forms an insulating microclimate between the layer of clothing and the body, which creates

118 an association of wool being a warm fibre. With a soft and natural touch it is comfortable to

119 wear, according to Tomar (2010). However, for sports applications wool is normally not the

120 first choice. A combination of natural and synthetic fibres in knitted and woven materials are

121 commonly used in sports garments. A cotton/polyester blend enhances durability, resilience,

122 and dimensional stability (Horrocks and Anand, 2000). Synthetic materials are generally

123 considered to be a good choice for sportswear as they are able to provide a valuable combination

124 of moisture management, softness, lightweight, and quick drying properties (Uttam, 2013).

125 Polyester e.g. is durable, yet light in weight, easy to care and a dimensionally stable material

126 that absorbs very little moisture and has a high resistance to stretching (Tomar, 2010; Uttam,

127 2013). Cotton on the other hand provides a good combination of softness and comfort, however

128 has a tendency to absorb and retain moisture (Uttam, 2013).

129 When purchasing online, it is important that the consumer has an understanding of what a

130 material is like to inform their choices. Therefore, understanding the knowledge of materials

131 that user have is important to aid the definition of the garment properties.

\section{Research questions}

134 Understanding consumers' perceptions of apparel's comfort is essential for providing (post 135 purchase) satisfaction. The purpose of the study is to identify factors influencing in-store 
136 purchases and establish those factors lacking in the emerging online environment irrespective

137 of sporting activity. Furthermore, the importance of comfort in sports garments and the

138 prioritisation of garment type in relation to comfort was investigated, as well as the consumer

139 attitudes towards specific textile materials in relation to sex and nationality. People from diverse

140 countries have different cultural norms that influence their perception and behaviour. Studies

141 comparing concept of comfort and textile fibre preferences in apparel products have not been

142 undertaken. Increased knowledge of preferences will contribute on garment designs to satisfy

143 the requirements of sports garment users. Based on the existing literature and reflecting current

144 comfort advances in garments as well as changing consumer behaviour, the following research

145 questions were developed.

$146 R Q_{1}$ : What are factors influencing the choice of online and in-store shopping?

$147 R Q_{2}$ : Is comfort an important attribute in the purchase of sports garments?

$148 R Q_{3}$ : Identification of the main attributes contributing to comfort and is there an influence of

149 sex and nationality?

$150 R Q_{4}:$ For which garment type is wear comfort most important?

$151 R Q_{5}:$ Does the amount of physical activity affect the comfort priorities of sport clothing?

$152 R Q_{6}:$ Is there a preconceived opinion regarding the feel of different textile materials?

\section{METHODS}

155 Data collection

156 A structured questionnaire was designed to explore clothing comfort in sports garments. Data 157 were collected through the Bristol Online Survey (BOS) tool (http://www.onlinesurveys.ac.uk).

158 Pilot-tests were carried out with academics as well as laypersons. The conceptual model for the 159 evaluation of the perception of comfort in sports garments derived from the evaluated literature. 
160 All procedures have been approved by the Loughborough University Ethics Approvals Sub-

161 Committee (Project-ID: 1257).

162 The survey comprised eight pages with a total of 18 questions. It started off with questions 163 regarding fitness level and type of physical activity typically undertaken. After that, the

164 individual purchase behaviour (online/in-store) was questioned, and respondents were asked to

165 report the three most important attributes when purchasing sports garments. If respondents 166 ticked 'comfort' as one of the three answers, the question 'How would you describe comfort in 167 sports garments for you?" was included to gather additional individual information. 168 Furthermore, the conceptualised hand-feel of sports t-shirts and consumer attitudes regarding 169 specific fibre types such as cotton, polyester, cotton/polyester blends and wool was investigated. Additional questions regarding attributes contributing to comfort in sports

171 garments and which types of garments ought to be most comfortable were asked.

172 Participants were recruited online using Facebook, LinkedIn, the Loughborough University 173 blackboard, and mailing lists within the Loughborough University. The survey was carried out 174 between the $20^{\text {th }}$ of April 2020 and $15^{\text {th }}$ of May 2020.

\section{Data analysis}

176 Respondents who did not wear sports garments ${ }^{1}$ were excluded from the study. A missing data

177 analysis was completed and resolved, and data evaluation was performed using descriptive 178 statistics. Frequency distributions and multiple response frequency analyses as well as 179 crosstabulations were run to investigate various interdependencies using SPSS version 26. For

180 the analysis of the research questions regarding the comparison of sex and nationality 181 (categorical data) a Chi-square $\left(\chi^{2}\right)$ test of independence (Pearson) was performed. Independent 182 variables were gender (male/female) and nationality. A probability level of $\mathrm{p}<0.05$ was defined

\footnotetext{
${ }^{1}$ For reporting purposes in this study, sports and exercise garments are referred to as sports garments
} 
183 as the threshold for significance. For the analysis of the open answer question, a qualitative data

184 analysis was performed using NVivo version 12 (12.6.0). A word frequency query was used to

185 identify themes and word trends.

187 RESULTS AND DISCUSSION

188 The final sample comprised 292 respondents, classified by sex, age, amount and kind of 189 physical activity undertaken, and nationality. A greater response sample of German and British

190 respondents was elicited; this was primarily due to the two research groups being based in these

191 countries. The representative sample is shown in Table I.

192 Table I here

193 The most popular sports activities among the participants are running, gym and outdoor sports.

194 It is most likely that factors such as changes in lifestyles and demographics, as well as physical

195 and mental benefits helped boosting outdoor sports activities. Running in particular provides

196 the opportunity to participate as an individual or a group at any time of the day or week without

197 the need of special equipment. Furthermore, environmental and educational trends support

198 getting active outdoors, especially with an increase in outdoor sporting events such as running 199 or cycling (Outdoor Industries Association and Sport England, 2015; Technavio, 2016; Iliades, 200 2018).

201

$202 R Q_{1}$ : What are factors influencing the choice of online and in-store shopping?

203 In-store purchases

204 Factors responsible for in-store purchase are sizing/fit $(91.4 \%)$, feel $(68.6 \%)$ and

205 look/appearance of the garment (54.3\%). When looking at the purchase behaviour in relation 206 to sex it is notable that there is a trend for females to purchase sports garments in a store because 
207 they are able to feel the garment (72.7\% females, $62.7 \%$ males). Females have a higher need 208 for tactile input when purchasing sports garments in a store. This is in line with a study of Citrin 209 et al. (2003) who found that more females, in comparison to males, require tactile input in 210 making product evaluations, and that individuals do not purchase clothing products online due 211 to a lack of accessibility to touch. However, the only significant difference between males and 212 females is look/appearance $\left(60.1 \%\right.$ females, $46.1 \%$ males, $\left.\chi^{2}(1)=4.5, p=0.034\right)$ and the 213 category 'other' $\left(\chi^{2}(1)=4.3, p=0.038\right)$, which mostly contained answers of purchasing 214 garments second hand. Regardless of sex, men and women differ on how they think, feel, and 215 act vis-à-vis their bodies. Females hold more negative body-image attitudes than males do and 216 place more cognitive and behavioural emphasis on managing their appearance (Cash and 217 Brown, 1989).

218 Online purchases

219 The biggest influencing factor for an online purchase is a cheaper price (63.2\%), followed by 220 convenience (58.0\%), less time consuming (53.3\%) and a greater range of designs (45.8\%). 221 Looking once more at a sex separation, it can be concluded that significantly more males buy 222 sports garments online due to a cheaper price $\left(73.5 \%\right.$ males, $54.4 \%$ females, $\chi^{2}(1)=7.6, p=$ $0.006)$ and significantly more females due to advertisements in social media $(21.9 \%$ females, $8.2 \%$ males, $\left.\chi^{2}(1)=7.8, p=0.005\right)$.

225 Sporting goods gained from the COVID-19 e-commerce boom of 2020. While consumers 226 shopped online before the pandemic, they were pushed to rely on digital retailers even more 227 during the COVID-19 lockdown periods, as many physical stores were closed (Palmer, 2021). 228 Furthermore, e-commerce is experiencing constant growth with globalisation being in motion 229 and social media as a big influencer. Facebook, Instagram, etc. are used to promote, market, 230 and sell products through the apps (Kulach, 2017; Mintel, 2018). Internet retailing increased its 231 share of sportswear sales in Western Europe as consumers have increasingly selected it for its 
232 easy price comparisons and convenience (Euromonitor, 2019). To push e-commerce further

233 sports companies could focus not only on stating information regarding the material 234 composition of the garment, but possibly on how the materials feel on the skin since this is a 235 missing crucial parameter when shopping online and a major factor when purchasing sports 236 garments in a store.

$R Q_{2}$ : Is comfort an important attribute in the purchase of sports garments?

239 When evaluating the question "What are the three most important attributes you look for when 240 purchasing sports garments" 'comfort' resulted in the second most frequent selected attribute $241(61.6 \%)$, just after fit (tight/loose) (63.7\%). The third and fourth most important attribute when 242 purchasing sports garments is price (45.5\%) followed by functionality (43.5\%). In the study of 243 Rahman (2011) investigating in the comfort of denim jeans, fit was also reported as the most 244 important and frequently mentioned attribute, followed by style, quality and comfort. Also 245 Zhang et al. (2002) found that fit, comfort, style, colour and workmanship were the most 246 important attributes in the purchase decisions of casual wear, however, geographic and 247 demographic factors had impacts on the perceptions. It is questionable, however, whether fit is 248 not already an integral part of the clothing comfort concept. Consumer demand for comfort is 249 nothing new nowadays, however, in the UK it became more prominent in 2019 (Euromonitor, 250 2020). Not only is it affecting the well-being, but also the performance and efficiency of athletes 251 and consumers, which ultimately influences their success (Bartels, 2011).

$R Q_{3}:$ Identification of the main attributes contributing to comfort and is there an influence of sex and nationality?

255 Respondents selected three to four answers on average to answer the question "what is comfort 256 in sports garments for you". Considering the overall responses, the three most important 
257 descriptors are freedom of movement (73.3\%), fit on the body $(60.3 \%)$ and a nice feel when 258 wearing the garment (58.6\%). If comfort had been selected in the previous question as one of 259 the three most important attributes, respondents were asked to describe comfort in sports 260 garments in their own words. The qualitative evaluation of the written words showed good 261 agreements with the fixed answer possibilities. The word cloud (Figure 1) is a visual 262 representation of the text data descriptions of comfort by the participants. The importance and 263 frequency of the keywords is shown with font size: Bigger terms have greater weight.

\section{Figure 1 here}

265 Feel and fit are the most prominent words, which moreover had obtained a high ranking in the 266 fixed answer question. Words were grouped together in stems for a clearer overall picture of 267 the total of 155 answer phrases. The least prominent words in the word cloud appear only once 268 in the overall answer phrases and were mostly combined with more prominent words. For 269 instance, "loose/baggy" with "fit" or "smooth/soft" with "feel". "Tight" was predominantly 270 used in a negative context; it was typically stated that garments should not be (too) tight. The 271 written phrases of the participants showed that fit is indeed integral part of the clothing comfort 272 concept.

273 The perception of comfort is further investigated by taking sex and nationality into account.

274 The sex division (Figure 2) shows that significantly more males prioritised physiological 275 comfort descriptors such as protection from environmental conditions $(52.7 \%$ males, 39.9\% 276 females, $\left.\chi^{2}(1)=4.8, p=0.029\right)$ and heat and moisture removal properties $(49.6 \%$ males, $36.2 \%$ 277 females, $\left.\chi^{2}(1)=5.3, p=0.021\right)$.

\section{$278 \quad$ Figure 2 here}

279 The comparison according to nationality shows a significantly different response rate for fit $\left(\chi^{2}\right.$ $280(1)=18.2, p=0.000)$ and feel $\left(\chi^{2}(1)=4.6, p=0.031\right)($ Figure 3$)$.

\section{$281 \quad$ Figure 3 here}


282 Significantly more British respondents selected fit on the body compared to Germans (79.2\% 283 and $50.5 \%$, respectively, $\left.\chi^{2}(1)=18.2, \mathrm{p}=0.000\right)$ and more Germans chose a nice feel when 284 wearing the garment compared to the British $\left(68.8 \%\right.$ and $54.2 \%$, respectively, $\chi^{2}(1)=4.6, p=$ 285 0.031). This was further investigated by looking at the interrelationship between German and 286 British females, and German and British males. In the category "when you do not even 287 recognize that you are wearing anything”, a significant difference was found between the 288 German and British males $\left(60.4 \%\right.$ and $35.1 \%$, respectively, $\left.\chi^{2}(1)=5.6, p=0.018\right)$. Within the 289 category "nice feel when wearing it" only males showed a significant difference (73.6\% 290 German males, 48.6\% British males, $\left.\chi^{2}(1)=5.8, p=0.016\right)$. Fit had a significant impact on 291 both German and British females $\left(\chi^{2}(1)=11.6, p=0.001\right)$ and German and British males $\left(\chi^{2}\right.$ $292(1)=5.9, p=0.015)$. It is reasonable to suggest that different cultural groups may show varying 293 responses due to interpersonal influences. In a study in six cities within China, respondents were asked to rank 15 different attributes on a 5-point-scale. The most important attributes were 295 fit, comfort, style, colour and workmanship. More importantly, the geographic location was 296 found to have an impact on the relevance of style, colour and brand (Zhang et al., 2002). People 297 from different countries have different cultural setups that motivate their (purchase) behaviour. 298 Even though the world is becoming more and more globally oriented, one has to stay culture 299 sensitive. There are cross-cultural differences and cross-cultural awareness is essential (Kulach, 2017).

$R Q_{4}:$ For which garment type is wear comfort most important?

303 Respondents were asked to select up to two garment types which ought to be the most 304 comfortable (Figure 4). Males selected t-shirt $\left(79.1 \%, \chi^{2}(1)=93.8, p=0.000\right)$, pants $(69.8 \%)$, $\left.305 \chi^{2}(1)=50.0, p=0.000\right)$ and socks $\left(27.9 \%, \chi^{2}(1)=25.7, p=0.000\right)$, whereas females selected 306 sports bras $\left(83.4 \%, \chi^{2}(1)=201.5, \mathrm{p}=0.000\right)$, leggings $\left(56.4 \%, \chi^{2}(1)=77.8, \mathrm{p}=0.000\right)$ and 
307 pants $(28.2 \%)$. Furthermore, significantly more males chose jacket $\left(\chi^{2}(1)=5.4, p=0.020\right)$. It

308 should be kept in mind that fewer males wear leggings and only females wear sports bras.

\section{Figure 4 here}

310 The outcome that female respondents consider that sports bras should be the most comfortable

311 sports garment is not surprising. Breast asymmetries as well as the variety of individual breast

312 shapes make it difficult to find well-fitted sports bras and general garment types for the upper

313 body of an individual female. Losken et al. (2005) also found that natural breast asymmetry

314 exists, and more precisely that differences in size and shape between the left and right breast

315 with the left breast being on average larger than the right.

316 Male participants stated that t-shirts and pants should be the most comfortable pieces of

317 clothing. T-shirts are of great relevance, since this type of garment, similar to sports bras for

318 females, is in direct contact with the skin. This is especially relevant when talking about

319 moisture management properties of textiles. The fabric close to the body, can take up sweat

320 from the skin and spread it to a larger area on the fabric, as well as transport it from the inner

321 to outer surface where heat loss due to evaporation takes place (Wang et al., 2013).

322 Surprisingly, socks also gained a higher percentage amongst male respondents. Socks are

323 regarded as an important component within the foot-shoe system and particularly of interest for

324 runners. Exercising without a sock enhance a perception of foot wetness, stickiness and thermal

325 discomfort. Socks have a positive impact on the reduction of tactile and mechanical inputs

326 generated between the foot and the shoe and is therefore relevant for the overall improvements

327 in foot-wear comfort (West et al., 2021). Furthermore, Barkley et al. (2011) investigated the

328 role of socks within the shoe-foot system and determined how the perception of comfort was

329 influenced during a treadmill run with different socks. The study found that even though foot

330 temperature did not differ statistically, participant perceptions of foot temperature did not

331 coincide with physiological foot temperature and are strongly influenced by sock 
332 characteristics. The outcome of these studies as well as the relatively high survey response rate

333 for socks amongst the male population indicates that socks are indeed relevant for the overall

334 improvements in comfort.

$R Q_{5}:$ Does the amount of physical activity affect the comfort priorities of sport clothing?

337 The overall evaluation of comfort priorities regarding the frequency of practising sports showed that people spending more time exercising (10+ hours) set priorities in garments differently; more precisely, they make higher demands on sports garments than respondents spending less

340 time practising sports (1-10 hours). The importance of the physiological comfort parameters in comparison to the psychological and physical ones is increased. This is plausible since efficient thermoregulation of the human body has critical influence not only on wear comfort but also on the sport performance. Fabric is not only a passive cover for the skin, it also modifies the

344 heat regulating functions of the body (Zhang et al., 2002). In a clothing system with poor 345 breathability, the heart rate and the rectal temperature of the person will increase much more rapidly than with breathable apparel (Umbach, 2001). Consequently, it is unlikely to withstand high levels of performance for a longer period of time in a non-optimal garment.

$R Q_{6}:$ Is there a preconceived opinion regarding the feel of different textile materials?

350 Throughout the survey participants relied on information about their previous experiences with 351 the fabrics. A consumer attitude regarding cotton, polyester, cotton/polyester blend and wool 352 was investigated and analysed (Figure 5). The characteristics for wool were warm-feeling 353 (73.6\%), scratchy (54.5\%), natural (51.7\%) and heavy-weight (46.6\%). Cotton is considered as 354 a natural (65.4\%), soft (53.8\%) and smooth (50\%) material with a warm feeling (46.2\%). 26.7\% 355 of respondents selected heavy-weight and 19.5\% light-weight. Polyester is judged as synthetic 356 (75\%), light-weight (62.7\%), and with a cold feeling (41.1\%). When analysing the results of 
357 the attitude towards the cotton/polyester blend, it is notable that the characteristics of cotton 358 and polyester, when considered separately, are present in a combined manner. Surprisingly, the 359 blend is mostly judged as synthetic $(32.9 \%, 8.2 \%$ natural $)$ with a similar number of respondents 360 selecting a warm- or cold-feeling. Possibly, it was difficult for respondents to distinguish 361 between a cold- and a warm-feeling without being able to touch appropriate textiles. The 362 number of respondents selecting 'not applicable' $(8.9 \%)$ indicates that some people were overstrained with characterising the feel of the cotton/polyester blend.

\section{$364 \quad$ Figure 5 here}

365 To further investigate the feel of the selected fibre types a separation was performed between 366 sex and nationality. There was a statistically significant difference in the way in which males 367 see cotton as heavy (34.1\% males, $20.9 \%$ females, $\left.\chi^{2}(1)=6.5, p=0.011\right)$ and warm $(55 \%$ males, $39.3 \%$ females, $\left.\chi^{2}(1)=17.1, p=0.000\right)$. Both, heavy-weight and warm-feeling in regard to sports clothing are attributes with negative associations.

Looking at German and British responses separately, there is no agreement in the 371 characterisation of cotton for its thermoregulating properties. Significantly more Germans 372 associate cotton with a warm-feeling $\left(\chi^{2}(1)=17.1, \mathrm{p}=0.000\right)$, significantly more British with a cold-feeling $\left(\chi^{2}(1)=15.3, p=0.000\right)$. This could possibly stem from cultural peculiarities where the presentation of materials in familiar surroundings could be different. The surface texture of cotton for instance can generally be smooth or brushed (e.g., in bed sheets). This 376 could have an influence on humans' thermal perception of textiles.

377 The attitude regarding polyester was significantly different amongst sex in the attributes of 378 cold-feeling $\left(35.0 \%\right.$ females, $48.8 \%$ males, $\left.\chi^{2}(1)=5.7, p=0.017\right)$ and stiff $(4.9 \%$ females, $3790.8 \%$ males, $\chi^{2}(1)=4.1, \mathrm{p}=0.042$ ). The comparison between Germans and British shows a 380 significant difference in the cold-feel (55.0\% Germans, $27.1 \%$ British, $\left.\chi^{2}(1)=16.4, p=0.000\right)$ 381 and scratchiness (5.5\% Germans, $14.6 \%$ British, $\left.\chi^{2}(1)=4.8, \mathrm{p}=0.029\right)$. 
382 The comparison of the cotton/polyester blend broken down by sex shows that significantly more 383 males perceive the material as silky $\left(17.8 \%\right.$ males, $9.8 \%$ females, $\left.\chi^{2}(1)=4.0, p=0.046\right)$. The 384 only significant difference between German and British respondents is light-weight (55.2\% 385 British, 34.9\% Germans, $\left.\chi^{2}(1)=8.6, p=0.003\right)$. Participants could have had difficulties 386 distinguishing whether a material is light- or heavy weight as they were not able to touch or lift 387 it, since besides cotton, also polyester and the cotton/polyester blend received high percentages 388 regarding light-weight. The determination of weight might additionally be challenging, since sport shirts in general are not being perceived as heavy in comparison to other garments humans 390 are used to wearing.

392 Assessing the overall selection of the most favourite fibre type (Figure 6), cotton, polyester and 393 the blend show similar popularity. Clearly wool is chosen as last in the left diagram (6.6\%) and received most percentage as the least favourite fibre type (right diagram: 72.8\%).

\section{$395 \quad$ Figure 6 here}

396 The results are once more split by sex and nationality (Figure 7). It seems that women prefer 397 cotton for sports garments (36.4\% females, $24.6 \%$ males) and significantly more males prefer 398 polyester $\left(34.1 \%\right.$ males, $22.2 \%$ females, $\left.\chi^{2}(1)=9.0, p=0.030\right)$. British respondents seem to 399 favour cotton (34.4\% British, 21.1\% Germans). This is in accordance with the study by Byrne 400 et al. (1993) who found that consumers in both Newcastle and Sydney preferred fibres for 401 sportshirts in the order of cotton, silk, polyester and nylon. They also found that UK students 402 expressed a wish for slightly softer, smoother and less resilient fabrics than the Sydney students. The effect of a preferred cotton material in females is present in both the German and the British 404 population. However, polyester was judged similarly by male and female British respondents 405 and the effect of a preferred polyester material in males is only existent in the German 406 population. These results lead to a conclusion that especially German males prefer t-shirts made 
407 out of polyester due to the cold touch and its light weight whereas females prioritise a warm, 408 soft-felt and natural material such as cotton. In a study by Byrne et al. (1993) they also found a 409 preference for natural fibres in female consumers. Furthermore, for some sports, such as yoga, 410 which had predominantly been selected by women ( $79.3 \%$ females, $20.7 \%$ males), there is 411 usually less demands for a functional textile having cooling effects but rather for a warm and 412 soft-felt material.

\section{$413 \quad$ Figure 7 here}

414 The comparison to the available literature additionally reinforces that garment comfort is 415 influenced by fibre type (Hyun et al., 1991). The hand feel of textiles is a crucial element 416 influencing the purchase decisions of garments by individuals (Ciesielska-Wróbel and Van 417 Langenhove, 2012). Furthermore, a study by Lee et al. (2003) confirms that nationality, age 418 and sex have an influence on the hand-feel of textiles. It is therefore important to analyse the 419 perception of materials regarding sex and nationality.

\section{IMPLICATION AND CONCLUSION}

422 Sportswear is subject to various demands, problems, and concerns. These can be anything from having a perfect fit on individual body proportions, supporting a comfortable feel on the skin, up to demanding a superior thermoregulatory function of the garment.

Nowadays, internet retailing is experiencing a growth due to cheaper prices, convenience and

426 the influence of social media. However, a missing factor when shopping online and a crucial 427 factor when shopping in a store is the ability to feel and perceive materials. Webpages are only stating the fibre composition of the garment; however, consumers must be knowledgeable about 429 the actual feel of the material.

430 When purchasing sports garments, consumers do not seek a single attribute, they often consider 431 multiple values within the product to satisfy their desires. Especially respondents practising 
432 sports more frequently (10+ hours per week) make higher functional demands on their sportive

433 equipment. The importance of the physiological comfort parameters in sports garments in

434 comparison to the psychological and physical ones are increased.

435 Furthermore, fit, and comfort are closely linked together, as fit is an integral part of the clothing

436 comfort concept. Females put more emphasis on garment fit than males. Additionally, females,

437 showed higher preference for tactile input in making product evaluations. Males, on the other

438 hand, prioritised physiological comfort descriptors for a good thermoregulatory support. There

439 was a trend where females had a more positive perception towards cotton and males towards

440 polyester.

441 The survey showed significant differences between German and British respondents regarding

442 attributes contributing to comfort and the perception of textile materials. The observed cultural

443 as well as sex nuances should be considered when developing sports garments for an

444 international market, since customers are the driving force behind product development. The

445 economic interests are big and drive towards innovation (Bielefeldt Bruun and Langkjær,

446 2016). For the apparel industry, information on product attributes from a consumer perspective

447 is crucial. A better understanding of the importance of different attributes in consumers' minds

448 helps an effective product development and marketing strategies (Zhang et al., 2002).

\section{TAKE HOME MESSAGES}

451 - E-commerce is experiencing constant growth; however, the haptics properties of 452 materials is a crucial missing parameter in the current online format

453 - Males prioritise physiological comfort descriptors for a good thermoregulatory support

454 - Higher physiological comfort demands on sports garments when practising 10+ hours of sports per week 
456 - Sex and nationality (German/British) has an impact on preferences; more precisely, on 457 the perception of parameters contributing to comfort as well as on the perception of 458 different textile materials (especially regarding cotton and polyester)

\section{LIMITATIONS}

461 The English language could have an influence on participants being born in non-native-English

462 speaking countries, since there was no translation of the survey into other languages.

463 Furthermore, the impersonality of online surveys is a critical factor. A face-to-face experiment

464 loses anonymity with an experimenter being present, which therefore produces a greater 465 commitment (Stieger et al., 2007).

466 In the scope of this research paper, no particular focus on a specific sports activity was set. Aim 467 was to gain initial insights in the perception of textile properties and set a basis for further haptic 468 research, e.g., specialist sports clothing such as compression garments or integrated protective 469 designs.

470 Additionally, further research on this topic could be conducted by distributing the survey 471 amongst a greater range of continents or countries. This would allow a broader comparison of 472 consumer expectations and perceptions on clothing comfort in sports garments in other, diverse 473 cultures. 


\section{REFERENCES}

475 Barkley, R. et al. (2011) 'Physiological Versus Perceived Foot Temperature, and Perceived

476 Comfort, during Treadmill Running in Shoes and Socks of Various Constructions', American

477 Journal of Undergraduate Research, 10(3). doi: 10.33697/ajur.2011.019.

478 Bartels, V. T. (2005) 'Physiological comfort of sportswear', in Shishoo, R. (ed.) Textiles in 479 Sport. Woodhead Publishing, pp. 177-203. doi: 10.1533/9781845690885.3.177.

480 Bartels, V. T. (2011) Improving comfort in sports and leisure wear, Improving Comfort in

481 Clothing. Edited by G. Song. Elsevier Masson SAS. doi: 10.1533/9780857090645.3.385.

482 BBC (2020) Nike expects permanent shift to online sales. Available at: 483 https://www.bbc.co.uk/news/business-54244967 (Accessed: 24 February 2021).

484 Bielefeldt Bruun, M. and Langkjær, M. A. (2016) 'Sportswear: Between Fashion, Innovation 485 and Sustainability', Fashion Practice. Routledge, 8(2), pp. 181-188. doi: 10.1080/17569370.2016.1221931.

Bishop, D. P. (1996) 'Fabrics: sensory and mechanical properties', Textile Topics, 26(3), pp. 1-62. doi: 10.1080/00405169608688866.

489 Byrne, M. S., Gardner, A. P. W. and Fritz, A. M. (1993) 'Fibre types and end-uses: A perceptual study', Journal of the Textile Institute, 84(2), pp. 275-288. doi: 10.1080/00405009308631269.

491 Cash, T. F. and Brown, T. A. (1989) 'Gender and body images: Stereotypes and realities', Sex 492 Roles, 21(5-6), pp. 361-373. doi: 10.1007/BF00289597.

493 Ciesielska-Wróbel, I. L. and Van Langenhove, L. (2012) 'The hand of textiles - definitions, 494 achievements, perspectives - a review', Textile Research Journal, 82(14), pp. 1457-1468. doi: 495 $10.1177 / 0040517512438126$.

496 Citrin, A. V. et al. (2003) 'Consumer need for tactile input: An internet retailing challenge', 497 Journal of Business Research, 56(11), pp. 915-922. doi: 10.1016/S0148-2963(01)00278-8. 498 Das, A. and Alagirusamy, R. (2010) Science in Clothing Comfort. Woodhead Publishing India 
499 Pvt. Ltd. doi: 10.1201/b18940.

500 Euromonitor (2019) Sportswear in Western Europe. Available at:

501 https://www.euromonitor.com/sportswear-in-western-europe/report (Accessed: 17 June 2020).

502 Euromonitor (2020) Apparel and Footwear in the United Kingdom. Available at:

503 https://www.euromonitor.com/apparel-and-footwear-in-the-united-kingdom/report (Accessed:

50417 June 2020).

505 Fiore, A. M. and Damhorst, M. L. (1992) 'Intrinsic cues as predictors of perceived quality of 506 apparel', Journal of Consumer Satisfaction, Dissatisfaction and Complaining Behavior, 5, pp. $507 \quad 168-178$.

508 Freire Castelo, J. S. and de Oliveira Cabral, J. E. (2018) 'Consumers in a social network: the 509 perception of clothing quality per gender', Revista Brasileira de Gestao de Negocios, 20(1), 510 pp. 22-36. doi: 10.7819/rbgn.v20i1.3684.

511 Hatch, K. L. and Roberts, J. A. (1985) 'Use of intrinsic and extrinsic cues to assess textile 512 product quality', Journal of Consumer Studies \& Home Economics, 9(4), pp. 341-357. doi: 513 10.1111/j.1470-6431.1985.tb00103.x.

514 Hines, J. D. and O’Neal, G. S. (1995) 'Underlying Determinants of Clothing Quality: The 515 Consumers' Perspective', Clothing and Textiles Research Journal, 13(4), pp. 227-233. doi: 10.1177/0887302X9501300403.

517 Horrocks, A. R. and Anand, S. C. (2000) Handbook of technical textiles. Cambridge: 518 Woodhead Publishing Limited.

519 Hyun, S. O., Hollies, N. R. S. and Spivak, S. M. (1991) 'Skin sensations perceived in apparel 520 wear Part I: Development of a new perception language', Journal of the Textile Institute, 82(3), pp. 387-397. doi: 10.1080/00405009108659223.

522 Iliades, C. (2018) Outdoor Exercise Can Boost the Body, Mind, and Mood. Available at: 523 https://www.everydayhealth.com/fitness/outdoor-exercise-benefits.aspx (Accessed: 10 August 
2020).

Kamalha, E. et al. (2013) 'The comfort dimension; A review of perception in clothing', Journal of Sensory Studies, 28, pp. 423-444.

Kulach, K. (2017) Germany vs UK: expert interview with P. Bijok on cultural differences in

528 ecommerce. Available at: https://www.webinterpret.com/uk/blog/germany-uk-expert-

529 interview-cultural-differences/ (Accessed: 17 June 2020).

530 Lee, S. et al. (2003) 'Active Tactual Motion of Fingers in Discriminating Cloth - The Difference 531 between Male and Female', Sen'i Gakkaishi, 59(9), pp. 365-370.

$532 \mathrm{Li}$, Y. (2005) 'Perceptions of temperature, moisture and comfort in clothing during 533 environmental transients', Ergonomics, 48(3), pp. 234-248. doi:

$534 \quad 10.1080 / 0014013042000327715$.

535 Losken, A. et al. (2005) 'An objective evaluation of breast symmetry and shape differences 536 using 3-dimensional images', Annals of Plastic Surgery, 55(6), pp. 571-575. doi: 537 10.1097/01.sap.0000185459.49434.5f.

538 McCann, J. (2015) Environmentally conscious fabric selection in sportswear design, Textiles

539 for Sportswear. Edited by R. Shishoo. Elsevier Ltd. doi: 10.1016/B978-1-78242-229-7.00002$540 \quad 3$.

541 Meyers, T. (2020) Global Activewear Market to Reach More Than \$350B in 2020. Available 542 at: https://wwd.com/business-news/business-features/global-activewear-market-to-reach543 more-than-350b-in-1234676717/ (Accessed: 2 March 2021).

544 Mintel (2018) Executive Summary - Sports \& Outdoor Fashion. United Kingdom.

545 Outdoor Industries Association and Sport England (2015) 'Getting Active Outdoors: A study 546 of Demography, Motivation, Participation and Provision in Outdoor Sport and Recreation in 547 England', Sport England, $\quad$ p. $57 . \quad$ Available at: 548 https://www.sportengland.org/media/3275/outdoors-participation-report-v2-lr-spreads.pdf. 
549 Palmer, A. (2021) Groceries and sporting goods were big gainers in the Covid e-commerce 550 boom of 2020. Available at: https://www.cnbc.com/2021/02/19/e-commerce-surged-during551 covid-groceries-sporting-goods-top-gainers-.html (Accessed: 24 February 2021).

552 Rahman, O. (2011) 'Understanding Consumers' Perceptions and Behaviors: Implications for 553 Denim Jeans Design', Journal of Textile and Apparel, Technology and Management, 7(1), pp. $554 \quad 1-16$.

555 Stieger, S., Reips, U.-D. and Voracek, M. (2007) 'Forced-Response in Online Surveys: Bias 556 from Reactance and an Increase in Sex-Specific Dropout', Journal of the American Society for 557 Information Science and Technology, 58(11), pp. 1653-1660. doi: 10.1002/asi.

558 Swinker, M. E. and Hines, J. D. (2006) 'Understanding consumers' perception of clothing 559 quality: A multidimensional approach', International Journal of Consumer Studies, 30(2), pp. 218-223. doi: 10.1111/j.1470-6431.2005.00478.x.

Technavio (2016) Increasing Participation in Outdoor Recreational Activities to Propel the 562 Global Outdoor Gear Market Through 2020. Available at: 563 https://www.businesswire.com/news/home/20160527005011/en/Increasing-Participation-

564 Outdoor-Recreational-Activities-Propel-Global (Accessed: 10 August 2020).

565 Tomar, R. S. (2010) 'Introduction to different fibres', Handbook of Worsted Wool and Blended $566 \quad$ Suiting Process, pp. 1-21. doi: 10.1533/9780857092809.1.

567 Umbach, K. H. (2001) 'Optimization of the wear comfort by suitable fibre, yarn and textile 568 construction', in 40th International Man-Made Fibres Congress. Dornbirn, Austria.

569 Uttam, D. (2013) 'Active sportswear fabrics', International Journal of IT, 2(1), pp. 34-40.

570 Wang, F. et al. (2013) 'Real evaporative cooling efficiency of one-layer tight-fitting sportswear

571 in a hot environment', Scandinavian Journal of Medicine and Science in Sports, 24(3), pp. 129572 139. doi: $10.1111 / \mathrm{sms} .12117$.

573 West, A. M., Havenith, G. and Hodder, S. (2021) 'Are running socks beneficial for comfort? 
574 The role of the sock and sock fiber type on shoe microclimate and subjective evaluations', 575 Textile Research Journal, 0(0), pp. 1-15. doi: 10.1177/0040517520986511.

576 Workman, J. E. and Cho, S. (2013) 'Gender, fashion consumer group, need for touch and

577 korean apparel consumers' shopping channel preference', International Journal of Consumer $578 \quad$ Studies, 37(5), pp. 522-529. doi: 10.1111/ijcs.12017.

579 Zhang, P. et al. (2002) 'Influence of clothing material properties on rectal temperature in 580 different environments', International Journal of Clothing Science and Technology, 14(5), pp. 581 299-306. doi: 10.1108/09556220210446112.

582 Zhang, Z. et al. (2002) 'Casual wear product attributes: A Chinese consumers' perspective',

583 Journal of Fashion Marketing and Management, 6(1), pp. 53-62. doi: $584 \quad 10.1108 / 13612020210422464$. 


\section{TITLE}

2 Consumer expectations and perception of clothing comfort in sports and exercise garments 


\section{ABSTRACT}

4 Purpose

5 Sports garments play an important role in the well-being of an athlete by protecting the wearer

6 from changing environmental conditions and providing a comfortable feel. Clothing

7 requirements have changed in recent years and demand for apparel with a higher comfort

8 performance have been rising. Hence, the purpose of this study was to explore consumers'

9 expectations and perception of comfort, and to examine how different textiles are perceived by consumers to provide useful knowledge that allows to engineer comfort into fabrics and sports

11 garments.

\section{Design/methodology/approach}

This online survey comprised 292 respondents, classified by sex, age, nationality, and physical activity. The respondents were asked a total of 18 questions through the Bristol Online Survey (BOS) tool to explore expectation, perception and preference of clothing comfort, specifically of sportswear.

\section{Findings}

Fit and comfort are closely linked together, both forming part of the clothing comfort concept. When purchasing garments online, the haptics of fabrics was identified as a crucial missing parameter. However, priorities of attributes within the concept varied according to the person's sex and nationality. Females put more emphasis on garment fit and showed higher need for tactile input, whereas males prioritised physiological comfort descriptors, i.e., properties which facilitate thermoregulation. Furthermore, there is an increased importance of physiological comfort parameters for people exercising for 10 or more hours per week. Finally, it was possible to identify common associations and preferences for textile materials (cotton, polyester, cotton/polyester blend and wool). However, consideration should be taken concerning sex and nationality. 


\section{Originality/value}

29 Sex and nationality are parameters modulating the clothing comfort concept and the 30 conceptualized feel of materials. Therefore, sex and nationality of the end-consumer should be

31 considered during the development phase of sports garments, and particular attention should be 32 given to the targeted market in which these will be sold.

33 KEY WORDS Clothing comfort, Sports garments, Purchase behaviour, Material perception,

34 Fibre preferences, Haptics

35 PAPER TYPE Research paper 


\section{INTRODUCTION}

The apparel industry faces challenges in satisfying consumers' need due to the change of priorities in the previous decades. During the 80 s and 90 s, consumers tended to buy fashionable clothing, whereas today, consumers are generally more value-orientated (Freire Castelo and de Oliveira Cabral, 2018). Understanding consumers' perceptions of apparel's quality is essential for providing satisfaction, which could lead to a potential competitive advantage, larger market share and higher revenue for apparel companies. In this regard, one clothing aspect that has to be studied and quantified is comfort. Human's perception of clothing comfort is made when sensory information is received, processed and then compared to past sensory experiences, ultimately representing people's expectations (Rahman, 2011; Freire Castelo and de Oliveira Cabral, 2018). These perceptions lead to the formulation of different clothing attributes, which have different importance for the consumers, and affect purchase decisions. Therefore, having a good understanding of these attributes can help in the product development phase and marketing strategies (Zhang et al., 2002).

\section{Literature review}

Past studies have focused on the evaluation of determinant attributes in the perception of apparel products. In a study by Zhang et al. (2002), it was found that fit, comfort, colour and workmanship were the most important attributes during the purchase decision of casual wear, and that perceptions were affected by geographic and demographic factors. The geographic location was found to impact attributes such as style, colour and brand; for instance, consumers in northern cities of China were relatively less concerned with colour, whereas consumers in Shanghai paid more attention to colour as well as brand name. Differences are difficult to pinpoint, however these can be traced back to tradition and culture. Furthermore, regarding sex, females place more emphasis on fit, comfort, style, colour, and easy care. 
61 Workman and Cho (2013) also indicated that individual preferences are affected by the culture in which a person is exposed to growing up, as well as individual differences such as sex. Additionally, females showed greater preferences for in-store shopping channels than men.

Many studies categorised attributes determining consumers' quality perceptions into two

general types: extrinsic and intrinsic cues (Hatch and Roberts, 1985). Intrinsic cues are inherent to the physical composition and cannot be modified without changing the overall product: fibre content, fabric structure, garment construction, quality, style, comfort, and fit. Extrinsic attributes are product related, however, are not part of the physical product. Examples for extrinsic cues are price, brand label, store, and country of origin (Hatch and Roberts, 1985; Swinker and Hines, 2006; Rahman, 2011; Freire Castelo and de Oliveira Cabral, 2018). In the perception of quality across a wide range of products intrinsic cues are considered to be more important than extrinsic ones (Fiore and Damhorst, 1992). This is consistent with findings by Rahman (2011), where intrinsic factors regarding denim products were found to play a more significant role than extrinsic factors.

Comfort in general is of multifactorial nature; in sports garments in particular it influences the overall performance and utility of the garment. A subdivision of three related major groups can be performed: psychological/ergonomic, physical (sensorial/tactile) and physiological comfort (Kamalha et al., 2013). The psychological/ergonomic comfort includes personal aspects such as personality and cultural background, as well as style, aesthetics, fashion, design, colour, fit, and freedom of movement (Bartels, 2005). The physical (sensorial/tactile) comfort refers to the skin-clothing interaction, which triggers various sensory receptors leading to a rise in psychophysical perception. Sensations felt can be tactile (smoothness, roughness, softness, stiffness, scratchiness), thermal (warmth, coolness, breathability), moisture (wetness, stickiness) and pressure sensations (lightweight, heaviness) (Bartels, 2005; Bishop, 1996; Das and Alagirusamy, 2010). Lastly, the physiological comfort refers to body thermoregulation ( $\mathrm{Li}$, 
2005). Rahman's (2011) interpretation of comfort in apparel products involves thermal effects of a garment (warmth, breathability), sensory characteristics (tactile feeling), and mobility (ease of movement). In a more recent study (McCann, 2015), comfort is defined as a combination of appropriate shape and fit, including freedom of movement, thermal regulation via moisture wicking and quick drying properties, as well as lightweight, protection and durability. These factors contributed to the overall 'feel good' factor for the wearer.

When purchasing a sports garment in a shop, direct involvement such as touching, feeling or trying-on the garment is a natural tendency before making a final purchase decision (Rahman, 2011). In-store shopping is still leading over online, however, online purchases have been catching up (Mintel, 2018) especially during the COVID-19 lockdown periods (March/April, October 2020, January 2021). Nike expects a permanent shift to online sales. The US company recorded a digital sales increase of $82 \%$ during the June to August quarter in 2020 (BBC, 2020). Similar to Nike, Adidas' online sales surge by $93 \%$ in the second quarter and $51 \%$ in the third (Meyers, 2020). Apparel companies have had to adapt to changing consumer behaviour during the pandemic by focussing on investments in online direct-to-consumer sales. It is therefore important to investigate people's purchase behaviour to be able to prioritise resources across different channels (e-commerce, physical stores). Regarding e-commerce, a big limiting factor could be represented by the difficulty to feel the garment by hand, especially if haptic response plays a major role in the purchase decision. In a study by Hines \& O’Neal (1995) consumers evaluated quality using attributes that they associated with social, psychological, economic, physiological, and aesthetic characteristics. When evaluating garment quality, fabric material was the only attribute identified by most of the participants. According to the study, if fabric does not meet the requirements and expectations, all other factors like aesthetic, economic/performance, physiological and social/psychological may become unimportant since fabric is an integral part of clothing. Fabric was perceived to have a noticeable effect on the 
111 overall appearance and performance of the garment. This is in accordance with Fiore \&

112 Damhorst (1992) who also stated that fabric is the best predictor of perceived quality of apparel.

113 Product information labels of sports garments are usually stating fibre content and finish, which

114 is helpful in the way of identifying the product composition; however, the consumer must be

115 knowledgeable about which properties are associated with each product component (Hatch and

116 Roberts, 1985). How are materials perceived in consumers' minds? Wool for instance traps air

117 and forms an insulating microclimate between the layer of clothing and the body, which creates

118 an association of wool being a warm fibre. With a soft and natural touch it is comfortable to

119 wear, according to Tomar (2010). However, for sports applications wool is normally not the

120 first choice. A combination of natural and synthetic fibres in knitted and woven materials are

121 commonly used in sports garments. A cotton/polyester blend enhances durability, resilience,

122 and dimensional stability (Horrocks and Anand, 2000). Synthetic materials are generally

123 considered to be a good choice for sportswear as they are able to provide a valuable combination

124 of moisture management, softness, lightweight, and quick drying properties (Uttam, 2013).

125 Polyester e.g. is durable, yet light in weight, easy to care and a dimensionally stable material

126 that absorbs very little moisture and has a high resistance to stretching (Tomar, 2010; Uttam,

127 2013). Cotton on the other hand provides a good combination of softness and comfort, however

128 has a tendency to absorb and retain moisture (Uttam, 2013).

129 When purchasing online, it is important that the consumer has an understanding of what a

130 material is like to inform their choices. Therefore, understanding the knowledge of materials

131 that user have is important to aid the definition of the garment properties.

\section{Research questions}

134 Understanding consumers' perceptions of apparel's comfort is essential for providing (post 135 purchase) satisfaction. The purpose of the study is to identify factors influencing in-store 
136 purchases and establish those factors lacking in the emerging online environment irrespective

137 of sporting activity. Furthermore, the importance of comfort in sports garments and the

138 prioritisation of garment type in relation to comfort was investigated, as well as the consumer

139 attitudes towards specific textile materials in relation to sex and nationality. People from diverse

140 countries have different cultural norms that influence their perception and behaviour. Studies

141 comparing concept of comfort and textile fibre preferences in apparel products have not been

142 undertaken. Increased knowledge of preferences will contribute on garment designs to satisfy

143 the requirements of sports garment users. Based on the existing literature and reflecting current

144 comfort advances in garments as well as changing consumer behaviour, the following research

145 questions were developed.

$146 R Q_{1}$ : What are factors influencing the choice of online and in-store shopping?

$147 R Q_{2}$ : Is comfort an important attribute in the purchase of sports garments?

$148 R Q_{3}$ : Identification of the main attributes contributing to comfort and is there an influence of

149 sex and nationality?

$150 R Q_{4}:$ For which garment type is wear comfort most important?

$151 R Q_{5}:$ Does the amount of physical activity affect the comfort priorities of sport clothing?

$152 R Q_{6}:$ Is there a preconceived opinion regarding the feel of different textile materials?

\section{METHODS}

155 Data collection

156 A structured questionnaire was designed to explore clothing comfort in sports garments. Data 157 were collected through the Bristol Online Survey (BOS) tool (http://www.onlinesurveys.ac.uk).

158 Pilot-tests were carried out with academics as well as laypersons. The conceptual model for the 159 evaluation of the perception of comfort in sports garments derived from the evaluated literature. 
160 All procedures have been approved by the Loughborough University Ethics Approvals Sub-

161 Committee (Project-ID: 1257).

162 The survey comprised eight pages with a total of 18 questions. It started off with questions 163 regarding fitness level and type of physical activity typically undertaken. After that, the

164 individual purchase behaviour (online/in-store) was questioned, and respondents were asked to

165 report the three most important attributes when purchasing sports garments. If respondents

166 ticked 'comfort' as one of the three answers, the question 'How would you describe comfort in

167 sports garments for you?" was included to gather additional individual information.

168 Furthermore, the conceptualised hand-feel of sports t-shirts and consumer attitudes regarding

169 specific fibre types such as cotton, polyester, cotton/polyester blends and wool was

170 investigated. Additional questions regarding attributes contributing to comfort in sports

171 garments and which types of garments ought to be most comfortable were asked.

172 Participants were recruited online using Facebook, LinkedIn, the Loughborough University

173 blackboard, and mailing lists within the Loughborough University. The survey was carried out

174 between the $20^{\text {th }}$ of April 2020 and $15^{\text {th }}$ of May 2020.

\section{Data analysis}

176 Respondents who did not wear sports garments ${ }^{1}$ were excluded from the study. A missing data

177 analysis was completed and resolved, and data evaluation was performed using descriptive 178 statistics. Frequency distributions and multiple response frequency analyses as well as 179 crosstabulations were run to investigate various interdependencies using SPSS version 26. For

180 the analysis of the research questions regarding the comparison of sex and nationality 181 (categorical data) a Chi-square $\left(\chi^{2}\right)$ test of independence (Pearson) was performed. Independent 182 variables were gender (male/female) and nationality. A probability level of $\mathrm{p}<0.05$ was defined

\footnotetext{
${ }^{1}$ For reporting purposes in this study, sports and exercise garments are referred to as sports garments
} 
183 as the threshold for significance. For the analysis of the open answer question, a qualitative data

184 analysis was performed using NVivo version 12 (12.6.0). A word frequency query was used to

185 identify themes and word trends.

187 RESULTS AND DISCUSSION

188 The final sample comprised 292 respondents, classified by sex, age, amount and kind of 189 physical activity undertaken, and nationality. A greater response sample of German and British

190 respondents was elicited; this was primarily due to the two research groups being based in these

191 countries. The representative sample is shown in Table I.

192 Table I here

193 The most popular sports activities among the participants are running, gym and outdoor sports.

194 It is most likely that factors such as changes in lifestyles and demographics, as well as physical

195 and mental benefits helped boosting outdoor sports activities. Running in particular provides

196 the opportunity to participate as an individual or a group at any time of the day or week without

197 the need of special equipment. Furthermore, environmental and educational trends support

198 getting active outdoors, especially with an increase in outdoor sporting events such as running 199 or cycling (Outdoor Industries Association and Sport England, 2015; Technavio, 2016; Iliades, 200 2018).

201

$202 R Q_{1}$ : What are factors influencing the choice of online and in-store shopping?

203 In-store purchases

204 Factors responsible for in-store purchase are sizing/fit $(91.4 \%)$, feel $(68.6 \%)$ and

205 look/appearance of the garment (54.3\%). When looking at the purchase behaviour in relation 206 to sex it is notable that there is a trend for females to purchase sports garments in a store because 
207 they are able to feel the garment (72.7\% females, $62.7 \%$ males). Females have a higher need 208 for tactile input when purchasing sports garments in a store. This is in line with a study of Citrin 209 et al. (2003) who found that more females, in comparison to males, require tactile input in 210 making product evaluations, and that individuals do not purchase clothing products online due 211 to a lack of accessibility to touch. However, the only significant difference between males and 212 females is look/appearance $\left(60.1 \%\right.$ females, $46.1 \%$ males, $\left.\chi^{2}(1)=4.5, p=0.034\right)$ and the 213 category 'other' $\left(\chi^{2}(1)=4.3, p=0.038\right)$, which mostly contained answers of purchasing 214 garments second hand. Regardless of sex, men and women differ on how they think, feel, and 215 act vis-à-vis their bodies. Females hold more negative body-image attitudes than males do and 216 place more cognitive and behavioural emphasis on managing their appearance (Cash and 217 Brown, 1989).

218 Online purchases

219 The biggest influencing factor for an online purchase is a cheaper price (63.2\%), followed by 220 convenience (58.0\%), less time consuming (53.3\%) and a greater range of designs (45.8\%). 221 Looking once more at a sex separation, it can be concluded that significantly more males buy 222 sports garments online due to a cheaper price $\left(73.5 \%\right.$ males, $54.4 \%$ females, $\chi^{2}(1)=7.6, p=$ $223 \quad 0.006)$ and significantly more females due to advertisements in social media (21.9\% females, $2248.2 \%$ males, $\left.\chi^{2}(1)=7.8, p=0.005\right)$.

225 Sporting goods gained from the COVID-19 e-commerce boom of 2020. While consumers 226 shopped online before the pandemic, they were pushed to rely on digital retailers even more 227 during the COVID-19 lockdown periods, as many physical stores were closed (Palmer, 2021). 228 Furthermore, e-commerce is experiencing constant growth with globalisation being in motion 229 and social media as a big influencer. Facebook, Instagram, etc. are used to promote, market, 230 and sell products through the apps (Kulach, 2017; Mintel, 2018). Internet retailing increased its 231 share of sportswear sales in Western Europe as consumers have increasingly selected it for its 
232 easy price comparisons and convenience (Euromonitor, 2019). To push e-commerce further

233 sports companies could focus not only on stating information regarding the material 234 composition of the garment, but possibly on how the materials feel on the skin since this is a 235 missing crucial parameter when shopping online and a major factor when purchasing sports 236 garments in a store.

$R Q_{2}:$ Is comfort an important attribute in the purchase of sports garments?

239 When evaluating the question "What are the three most important attributes you look for when 240 purchasing sports garments" 'comfort' resulted in the second most frequent selected attribute 241 (61.6\%), just after fit (tight/loose) (63.7\%). The third and fourth most important attribute when 242 purchasing sports garments is price (45.5\%) followed by functionality (43.5\%). In the study of 243 Rahman (2011) investigating in the comfort of denim jeans, fit was also reported as the most 244 important and frequently mentioned attribute, followed by style, quality and comfort. Also 245 Zhang et al. (2002) found that fit, comfort, style, colour and workmanship were the most 246 important attributes in the purchase decisions of casual wear, however, geographic and 247 demographic factors had impacts on the perceptions. It is questionable, however, whether fit is 248 not already an integral part of the clothing comfort concept. Consumer demand for comfort is 249 nothing new nowadays, however, in the UK it became more prominent in 2019 (Euromonitor, 250 2020). Not only is it affecting the well-being, but also the performance and efficiency of athletes 251 and consumers, which ultimately influences their success (Bartels, 2011).

$R Q_{3}:$ Identification of the main attributes contributing to comfort and is there an influence of sex and nationality?

255 Respondents selected three to four answers on average to answer the question "what is comfort 256 in sports garments for you". Considering the overall responses, the three most important 
257 descriptors are freedom of movement (73.3\%), fit on the body $(60.3 \%)$ and a nice feel when 258 wearing the garment (58.6\%). If comfort had been selected in the previous question as one of 259 the three most important attributes, respondents were asked to describe comfort in sports 260 garments in their own words. The qualitative evaluation of the written words showed good 261 agreements with the fixed answer possibilities. The word cloud (Figure 1) is a visual 262 representation of the text data descriptions of comfort by the participants. The importance and 263 frequency of the keywords is shown with font size: Bigger terms have greater weight.

\section{Figure 1 here}

265 Feel and fit are the most prominent words, which moreover had obtained a high ranking in the 266 fixed answer question. Words were grouped together in stems for a clearer overall picture of 267 the total of 155 answer phrases. The least prominent words in the word cloud appear only once 268 in the overall answer phrases and were mostly combined with more prominent words. For 269 instance, "loose/baggy" with "fit" or "smooth/soft" with "feel". "Tight" was predominantly 270 used in a negative context; it was typically stated that garments should not be (too) tight. The 271 written phrases of the participants showed that fit is indeed integral part of the clothing comfort 272 concept.

273 The perception of comfort is further investigated by taking sex and nationality into account.

274 The sex division (Figure 2) shows that significantly more males prioritised physiological 275 comfort descriptors such as protection from environmental conditions $(52.7 \%$ males, 39.9\% 276 females, $\left.\chi^{2}(1)=4.8, p=0.029\right)$ and heat and moisture removal properties $(49.6 \%$ males, $36.2 \%$ $277 \quad$ females, $\left.\chi^{2}(1)=5.3, p=0.021\right)$.

\section{Figure 2 here}

279 The comparison according to nationality shows a significantly different response rate for fit $\left(\chi^{2}\right.$ $280 \quad(1)=18.2, p=0.000)$ and feel $\left(\chi^{2}(1)=4.6, p=0.031\right)$ (Figure 3).

\section{$281 \quad$ Figure 3 here}


282 Significantly mMore British respondents selected fit on the body compared to Germans (79.2\%

283 and $50.5 \%$, respectively, $\left.\chi^{2}(1)=18.2, p=0.000\right)$ and more Germans chose a nice feel when 284 wearing the garment compared to the British $\left(68.8 \%\right.$ and $54.2 \%$, respectively, $\chi^{2}(1)=4.6, p=$ 285 0.031). This was further investigated by looking at the interrelationship between German and 286 British females, and German and British males. In the category "when you do not even 287 recognize that you are wearing anything", a significant difference was found between the 288 German and British males $\left(60.4 \%\right.$ and $35.1 \%$, respectively, $\left.\chi^{2}(1)=5.6, p=0.018\right)$. Within the 289 category "nice feel when wearing it" only males showed a significant difference (73.6\% 290 German males, 48.6\% British males, $\left.\chi^{2}(1)=5.8, p=0.016\right)$. Fit had a significant impact on 291 both female-German and female-British females $\left(\chi^{2}(1)=11.6, p=0.001\right)$ and male-Germans 292 and male-British males $\left(\chi^{2}(1)=5.9, p=0.015\right)$, German and British. It is reasonable to suggest 293 that different cultural groups may show varying responses due to interpersonal influences. In a 294 study in six cities within China, respondents were asked to rank 15 different attributes on a 5295 point-scale. The most important attributes were fit, comfort, style, colour and workmanship. 296 More importantly, the geographic location was found to have an impact on the relevance of 297 style, colour and brand (Zhang et al., 2002). People from different countries have different 298 cultural setups that motivate their (purchase) behaviour. Even though the world is becoming 299 more and more globally oriented, one has to stay culture sensitive. There are cross-cultural 300 differences and cross-cultural awareness is essential (Kulach, 2017).

$302 R Q_{4}:$ For which garment type is wear comfort most important?

303 Respondents were asked to select up to two garment types which ought to be the most 304 comfortable (Figure 4). Males selected t-shirt $\left(79.1 \%, \chi^{2}(1)=93.8, p=0.000\right)$, pants $(69.8 \%)$, $\left.305 \quad \chi^{2}(1)=50.0, p=0.000\right)$ and socks $\left(27.9 \%, \chi^{2}(1)=25.7, p=0.000\right)$, whereas females selected 306 sports bras $\left(83.4 \%, \chi^{2}(1)=201.5, p=0.000\right)$, leggings $\left(56.4 \%, \chi^{2}(1)=77.8, p=0.000\right)$ and 
307 pants (28.2\%). Furthermore, significantly more males chose jacket $\left(\chi^{2}(1)=5.4, p=0.020\right)$.

308 However, - Iit should be kept in mind that fewer males wear leggings and only females wear 309 sports bras.

$310 \quad$ Figure 4 here

311 The outcome that female respondents consider that sports bras should be the most comfortable 312 sports garment is not surprising. Breast asymmetries as well as the variety of individual breast 313 shapes make it difficult to find well-fitted sports bras and general garment types for the upper 314 body of an individual female. Losken et al. (2005) also found that natural breast asymmetry 315 exists, and more precisely that differences in size and shape between the left and right breast 316 with the left breast being on average larger than the right.

317 Male participants stated that t-shirts and pants should be the most comfortable pieces of 318 clothing. T-shirts are of great relevance, since this type of garment, similar to sports bras for 319 females, is in direct contact with the skin. This is especially relevant when talking about 320 moisture management properties of textiles. The fabric close to the body, can take up sweat 321 from the skin and spread it to a larger area on the fabric, as well as transport it from the inner 322 to outer surface where heat loss due to evaporation takes place (Wang et al., 2013). 323 Surprisingly, socks also gained a higher percentage amongst male respondents. Socks are 324 regarded as an important component within the foot-shoe system and particularly of interest for 325 runners. Exercising without a sock enhance a perception of foot wetness, stickiness and thermal 326 discomfort. Socks have a positive impact on the reduction of tactile and mechanical inputs 327 generated between the foot and the shoe and is therefore relevant for the overall improvements 328 in foot-wear comfort (West et al., 2021). Furthermore, Barkley et al. (2011) investigated the 329 role of socks within the shoe-foot system and determined how the perception of comfort was 330 influenced during a treadmill run with different socks. The study found that even though foot 331 temperature did not differ statistically, participant perceptions of foot temperature did not 
332 coincide with physiological foot temperature and are strongly influenced by sock

333 characteristics. The outcome of these studies as well as the relatively high survey response rate 334 for socks amongst the male population indicates that socks are indeed relevant for the overall 335 improvements in comfort.

$R Q_{5}:$ Does the amount of physical activity affect the comfort priorities of sport clothing?

338 The overall evaluation of comfort priorities regarding the frequency of practising sports showed 339 that people spending more time exercising (10+ hours) set priorities in garments differently; 340 more precisely, they make higher demands on sports garments than respondents spending less time practising sports (1-10 hours). The importance of the physiological comfort parameters in comparison to the psychological and physical ones is increased. This is plausible since efficient thermoregulation of the human body has critical influence not only on wear comfort but also on the sport performance. Fabric is not only a passive cover for the skin, it also modifies the heat regulating functions of the body (Zhang et al., 2002). In a clothing system with poor breathability, the heart rate and the rectal temperature of the person will increase much more rapidly than with breathable apparel (Umbach, 2001). Consequently, it is unlikely to withstand high levels of performance for a longer period of time in a non-optimal garment.

$R Q_{6}:$ Is there a preconceived opinion regarding the feel of different textile materials?

351 Throughout the survey participants relied on information about their previous experiences with 352 the fabrics. A consumer attitude regarding cotton, polyester, cotton/polyester blend and wool 353 was investigated and analysed (Figure 5). The characteristics for wool were warm-feeling 354 (73.6\%), scratchy (54.5\%), natural (51.7\%) and heavy-weight (46.6\%). Cotton is considered as 355 a natural (65.4\%), soft (53.8\%) and smooth (50\%) material with a warm feeling (46.2\%). 26.7\% 356 of respondents selected heavy-weight and 19.5\% light-weight. Polyester is judged as synthetic 
357 (75\%), light-weight (62.7\%), and with a cold feeling (41.1\%). When analysing the results of 358 the attitude towards the cotton/polyester blend, it is notable that the characteristics of cotton 359 and polyester, when considered separately, are present in a combined manner. Surprisingly, the 360 blend is mostly judged as synthetic (32.9\%, 8.2\% natural) with a similar number of respondents 361 selecting a warm- or cold-feeling. Possibly, it was difficult for respondents to distinguish 362 between a cold- and a warm-feeling without being able to touch appropriate textiles. The 363 number of respondents selecting 'not applicable' (8.9\%) indicates that some people were 364 overstrained with characterising the feel of the cotton/polyester blend.

\section{$365 \quad$ Figure 5 here}

366 To further investigate the feel of the selected fibre types a separation was performed between 367 sex and nationality. There was a statistically significant difference in the way in which males 368 see cotton as heavy (34.1\% males, $20.9 \%$ females, $\left.\chi^{2}(1)=6.5, p=0.011\right)$ and warm $(55 \%$ males, $39.3 \%$ females, $\left.\chi^{2}(1)=17.1, p=0.000\right)$. Both, heavy-weight and warm-feeling in regard to sports clothing are attributes with negative associations.

371 Looking at German and British responses separately, there is no agreement in the 372 characterisation of cotton for its thermoregulating properties. Significantly mMore Germans associate cotton with a warm-feeling $\left(\chi^{2}(1)=17.1, p=0.000\right)$, significantly hereas-more

374 British with a cold-feeling $\left(\chi^{2}(1)=15.3, p=0.000\right)$. This could possibly stem from cultural peculiarities where the presentation of materials in familiar surroundings could be different.

376 The surface texture of cotton for instance can generally be smooth or brushed (e.g., in bed 377 sheets). This could have an influence on humans' thermal perception of textiles.

378 The attitude regarding polyester was significantly different amongst sex in the attributes of 379 cold-feeling (35.0\% females, $48.8 \%$ males, $\left.\chi^{2}(1)=5.7, p=0.017\right)$ and stiff $(4.9 \%$ females, $380 \quad 0.8 \%$ males, $\chi^{2}(1)=4.1, p=0.042$ ). The comparison between Germans and British shows a 
381 significant difference in the cold-feel (55.0\% Germans, $27.1 \%$ British, $\left.\chi^{2}(1)=16.4, p=0.000\right)$

382 and scratchiness (5.5\% Germans, $14.6 \%$ British, $\left.\chi^{2}(1)=4.8, p=0.029\right)$.

383 The comparison of the cotton/polyester blend broken down by sex shows that significantly more 384 males perceive the material as silky $\left(17.8 \%\right.$ males, $9.8 \%$ females, $\left.\chi^{2}(1)=4.0, p=0.046\right)$. The 385 only significant difference between German and British respondents is light-weight (55.2\% 386 British, 34.9\% Germans, $\left.\chi^{2}(1)=8.6, p=0.003\right)$. Participants could have had difficulties 387 distinguishing whether a material is light- or heavy weight as they were not able to touch or lift 388 it, since besides cotton, also polyester and the cotton/polyester blend received high percentages 389 regarding light-weight. The determination of weight might additionally be challenging, since 390 sport shirts in general are not being perceived as heavy in comparison to other garments humans 391 are used to wearing.

Assessing the overall selection of the most favourite fibre type (Figure 6), cotton, polyester and 394 the blend show similar popularity. Clearly wool is chosen as last in the left diagram (6.6\%) and 395 received most percentage as the least favourite fibre type (right diagram: $72.8 \%$ ).

\section{Figure 6 here}

397 The results are once more split by sex and nationality (Figure 7). It seems that women prefer 398 cotton for sports garments (36.4\% females, $24.6 \%$ males) and significantly more males prefer 399 polyester $\left(34.1 \%\right.$ males, $22.2 \%$ females, $\left.\chi^{2}(1)=9.0, p=0.030\right)$. British respondents seem to 400 favour cotton (34.4\% British, 21.1\% Germans). This is in accordance with the study by Byrne 401 et al. (1993) who found that consumers in both Newcastle and Sydney preferred fibres for 402 sportshirts in the order of cotton, silk, polyester and nylon. They also found that UK students expressed a wish for slightly softer, smoother and less resilient fabrics than the Sydney students.

404 The effect of a preferred cotton material in females is present in both the German and the British 405 population. However, polyester was judged similarly by male and female British respondents 
406 and the effect of a preferred polyester material in males is only existent in the German

407 population. These results lead to a conclusion that especially German males prefer t-shirts made 408 out of polyester due to the cold touch and its light weight whereas females prioritise a warm, 409 soft-felt and natural material such as cotton. In a study by Byrne et al. (1993) they also found a 410 preference for natural fibres in female consumers. Furthermore, for some sports, such as yoga, 411 which had predominantly been selected by women ( $79.3 \%$ females, $20.7 \%$ males), there is 412 usually less demands for a functional textile having cooling effects but rather for a warm and 413 soft-felt material.

\section{$414 \quad$ Figure 7 here}

415 The comparison to the available literature additionally reinforces that garment comfort is 416 influenced by fibre type (Hyun et al., 1991). The hand feel of textiles is a crucial element 417 influencing the purchase decisions of garments by individuals (Ciesielska-Wróbel and Van 418 Langenhove, 2012). Furthermore, a study by Lee et al. (2003) confirms that nationality, age 419 and sex have an influence on the hand-feel of textiles. It is therefore important to analyse the 420 perception of materials regarding sex and nationality.

\section{IMPLICATION AND CONCLUSION}

Sportswear is subject to various demands, problems, and concerns. These can be anything from having a perfect fit on individual body proportions, supporting a comfortable feel on the skin, up to demanding a superior thermoregulatory function of the garment.

426 Nowadays, internet retailing is experiencing a growth due to cheaper prices, convenience and 427 the influence of social media. However, a missing factor when shopping online and a crucial 428 factor when shopping in a store is the ability to feel and perceive materials. Webpages are only 429 stating the fibre composition of the garment; however, consumers must be knowledgeable about 430 the actual feel of the material. 
431 When purchasing sports garments, consumers do not seek a single attribute, they often consider

432 multiple values within the product to satisfy their desires. Especially respondents practising 433 sports more frequently (10+ hours per week) make higher functional demands on their sportive 434 equipment. The importance of the physiological comfort parameters in sports garments in 435 comparison to the psychological and physical ones are increased.

436 Furthermore, fit, and comfort are closely linked together, as fit is an integral part of the clothing 437 comfort concept. Females put more emphasis on garment fit than males. Additionally, females, 438 showed higher preference for tactile input in making product evaluations. Males, on the other 439 hand, prioritised physiological comfort descriptors for a good thermoregulatory support. There 440 was a trend where females had a more positive perception towards cotton and males towards 441 polyester.

442 The survey showed significant differences between German and British respondents regarding 443 attributes contributing to comfort and the perception of textile materials. The observed cultural 444 as well as sex nuances should be considered when developing sports garments for an 445 international market, since customers are the driving force behind product development. The 446 economic interests are big and drive towards innovation (Bielefeldt Bruun and Langkjær, 447 2016). For the apparel industry, information on product attributes from a consumer perspective 448 is crucial. A better understanding of the importance of different attributes in consumers' minds 449 helps an effective product development and marketing strategies (Zhang et al., 2002).

\section{TAKE HOME MESSAGES}

452 - E-commerce is experiencing constant growth; however, the haptics properties of 453 materials is a crucial missing parameter in the current online format $454 \quad$ - Males prioritise physiological comfort descriptors for a good thermoregulatory support 
- Higher physiological comfort demands on sports garments when practising 10+ hours of sports per week

- Sex and nationality (German/British) has an impact on preferences; more precisely, on the perception of parameters contributing to comfort as well as on the perception of 460

\section{LIMITATIONS}

The English language could have an influence on participants being born in non-native-English

463 speaking countries, since there was no translation of the survey into other languages.

464 Furthermore, the impersonality of online surveys is a critical factor. A face-to-face experiment 465 loses anonymity with an experimenter being present, which therefore produces a greater 466 commitment (Stieger et al., 2007).

467 In the scope of this research paper, no particular focus on a specific sports activity was set. Aim 468 was to gain initial insights in the perception of textile properties and set a basis for further haptic 469 research, e.g., specialist sports clothing such as compression garments or integrated protective 470 designs.

471 Additionally, further research on this topic could be conducted by distributing the survey 472 amongst a greater range of continents or countries. This would allow a broader comparison of 473 consumer expectations and perceptions on clothing comfort in sports garments in other, diverse 474 cultures. 


\section{REFERENCES}

476 Barkley, R. et al. (2011) 'Physiological Versus Perceived Foot Temperature, and Perceived

477 Comfort, during Treadmill Running in Shoes and Socks of Various Constructions', American 478 Journal of Undergraduate Research, 10(3). doi: 10.33697/ajur.2011.019.

479 Bartels, V. T. (2005) 'Physiological comfort of sportswear', in Shishoo, R. (ed.) Textiles in 480 Sport. Woodhead Publishing, pp. 177-203. doi: 10.1533/9781845690885.3.177.

481 Bartels, V. T. (2011) Improving comfort in sports and leisure wear, Improving Comfort in 482 Clothing. Edited by G. Song. Elsevier Masson SAS. doi: 10.1533/9780857090645.3.385.

483 BBC (2020) Nike expects permanent shift to online sales. Available at: 484 https://www.bbc.co.uk/news/business-54244967 (Accessed: 24 February 2021).

485 Bielefeldt Bruun, M. and Langkjær, M. A. (2016) 'Sportswear: Between Fashion, Innovation 486 and Sustainability', Fashion Practice. Routledge, 8(2), pp. 181-188. doi: 10.1080/17569370.2016.1221931.

Bishop, D. P. (1996) 'Fabrics: sensory and mechanical properties', Textile Topics, 26(3), pp. 1-62. doi: 10.1080/00405169608688866.

490 Byrne, M. S., Gardner, A. P. W. and Fritz, A. M. (1993) 'Fibre types and end-uses: A perceptual study', Journal of the Textile Institute, 84(2), pp. 275-288. doi: 10.1080/00405009308631269. Roles, 21(5-6), pp. 361-373. doi: 10.1007/BF00289597.

494 Ciesielska-Wróbel, I. L. and Van Langenhove, L. (2012) 'The hand of textiles - definitions, 495 achievements, perspectives - a review', Textile Research Journal, 82(14), pp. 1457-1468. doi: $10.1177 / 0040517512438126$.

497 Citrin, A. V. et al. (2003) 'Consumer need for tactile input: An internet retailing challenge', 498 Journal of Business Research, 56(11), pp. 915-922. doi: 10.1016/S0148-2963(01)00278-8. 499 Das, A. and Alagirusamy, R. (2010) Science in Clothing Comfort. Woodhead Publishing India 
500 Pvt. Ltd. doi: 10.1201/b18940.

501 Euromonitor (2019) Sportswear in Western Europe. Available at:

502 https://www.euromonitor.com/sportswear-in-western-europe/report (Accessed: 17 June 2020).

503 Euromonitor (2020) Apparel and Footwear in the United Kingdom. Available at:

504 https://www.euromonitor.com/apparel-and-footwear-in-the-united-kingdom/report (Accessed:

50517 June 2020).

506 Fiore, A. M. and Damhorst, M. L. (1992) 'Intrinsic cues as predictors of perceived quality of 507 apparel', Journal of Consumer Satisfaction, Dissatisfaction and Complaining Behavior, 5, pp. $508 \quad 168-178$.

509 Freire Castelo, J. S. and de Oliveira Cabral, J. E. (2018) 'Consumers in a social network: the 510 perception of clothing quality per gender', Revista Brasileira de Gestao de Negocios, 20(1), 511 pp. 22-36. doi: 10.7819/rbgn.v20i1.3684.

512 Hatch, K. L. and Roberts, J. A. (1985) 'Use of intrinsic and extrinsic cues to assess textile 513 product quality', Journal of Consumer Studies \& Home Economics, 9(4), pp. 341-357. doi: 514 10.1111/j.1470-6431.1985.tb00103.x.

515 Hines, J. D. and O’Neal, G. S. (1995) 'Underlying Determinants of Clothing Quality: The 516 Consumers' Perspective', Clothing and Textiles Research Journal, 13(4), pp. 227-233. doi: 10.1177/0887302X9501300403.

518 Horrocks, A. R. and Anand, S. C. (2000) Handbook of technical textiles. Cambridge: 519 Woodhead Publishing Limited.

520 Hyun, S. O., Hollies, N. R. S. and Spivak, S. M. (1991) 'Skin sensations perceived in apparel 521 wear Part I: Development of a new perception language', Journal of the Textile Institute, 82(3), pp. 387-397. doi: 10.1080/00405009108659223.

523 Iliades, C. (2018) Outdoor Exercise Can Boost the Body, Mind, and Mood. Available at: 524 https://www.everydayhealth.com/fitness/outdoor-exercise-benefits.aspx (Accessed: 10 August 
2020).

526 Kamalha, E. et al. (2013) 'The comfort dimension; A review of perception in clothing', Journal 527 of Sensory Studies, 28, pp. 423-444.

528 Kulach, K. (2017) Germany vs UK: expert interview with P. Bijok on cultural differences in 529 ecommerce. Available at: https://www.webinterpret.com/uk/blog/germany-uk-expert530 interview-cultural-differences/ (Accessed: 17 June 2020).

531 Lee, S. et al. (2003) 'Active Tactual Motion of Fingers in Discriminating Cloth - The Difference 532 between Male and Female', Sen'i Gakkaishi, 59(9), pp. 365-370.

533 Li, Y. (2005) 'Perceptions of temperature, moisture and comfort in clothing during 534 environmental transients', Ergonomics, 48(3), pp. 234-248. doi: $535 \quad 10.1080 / 0014013042000327715$.

536 Losken, A. et al. (2005) 'An objective evaluation of breast symmetry and shape differences 537 using 3-dimensional images', Annals of Plastic Surgery, 55(6), pp. 571-575. doi: 10.1097/01.sap.0000185459.49434.5f.

539 McCann, J. (2015) Environmentally conscious fabric selection in sportswear design, Textiles

540 for Sportswear. Edited by R. Shishoo. Elsevier Ltd. doi: 10.1016/B978-1-78242-229-7.000025413.

542 Meyers, T. (2020) Global Activewear Market to Reach More Than \$350B in 2020. Available 543 at: https://wwd.com/business-news/business-features/global-activewear-market-to-reach544 more-than-350b-in-1234676717/ (Accessed: 2 March 2021).

545 Mintel (2018) Executive Summary - Sports \& Outdoor Fashion. United Kingdom.

546 Outdoor Industries Association and Sport England (2015) 'Getting Active Outdoors: A study 547 of Demography, Motivation, Participation and Provision in Outdoor Sport and Recreation in 548 England', Sport England, 57 Available at: 549 https://www.sportengland.org/media/3275/outdoors-participation-report-v2-lr-spreads.pdf. 
550 Palmer, A. (2021) Groceries and sporting goods were big gainers in the Covid e-commerce 551 boom of 2020. Available at: https://www.cnbc.com/2021/02/19/e-commerce-surged-during552 covid-groceries-sporting-goods-top-gainers-.html (Accessed: 24 February 2021).

553 Rahman, O. (2011) 'Understanding Consumers' Perceptions and Behaviors: Implications for 554 Denim Jeans Design', Journal of Textile and Apparel, Technology and Management, 7(1), pp. $5551-16$.

556 Stieger, S., Reips, U.-D. and Voracek, M. (2007) 'Forced-Response in Online Surveys: Bias 557 from Reactance and an Increase in Sex-Specific Dropout', Journal of the American Society for 558 Information Science and Technology, 58(11), pp. 1653-1660. doi: 10.1002/asi.

559 Swinker, M. E. and Hines, J. D. (2006) 'Understanding consumers' perception of clothing 560 quality: A multidimensional approach', International Journal of Consumer Studies, 30(2), pp. 561 218-223. doi: 10.1111/j.1470-6431.2005.00478.x.

562 Technavio (2016) Increasing Participation in Outdoor Recreational Activities to Propel the 563 Global Outdoor Gear Market Through 2020. Available at:

$564 \mathrm{https}: / / \mathrm{www}$. businesswire.com/news/home/20160527005011/en/Increasing-Participation-

565 Outdoor-Recreational-Activities-Propel-Global (Accessed: 10 August 2020).

566 Tomar, R. S. (2010) 'Introduction to different fibres', Handbook of Worsted Wool and Blended $567 \quad$ Suiting Process, pp. 1-21. doi: 10.1533/9780857092809.1.

568 Umbach, K. H. (2001) 'Optimization of the wear comfort by suitable fibre, yarn and textile 569 construction', in 40th International Man-Made Fibres Congress. Dornbirn, Austria.

570 Uttam, D. (2013) 'Active sportswear fabrics', International Journal of IT, 2(1), pp. 34-40.

571 Wang, F. et al. (2013) 'Real evaporative cooling efficiency of one-layer tight-fitting sportswear

572 in a hot environment', Scandinavian Journal of Medicine and Science in Sports, 24(3), pp. 129573 139. doi: $10.1111 / \mathrm{sms} .12117$.

574 West, A. M., Havenith, G. and Hodder, S. (2021) 'Are running socks beneficial for comfort? 
575 The role of the sock and sock fiber type on shoe microclimate and subjective evaluations',

576 Textile Research Journal, 0(0), pp. 1-15. doi: 10.1177/0040517520986511.

577 Workman, J. E. and Cho, S. (2013) 'Gender, fashion consumer group, need for touch and

578 korean apparel consumers' shopping channel preference', International Journal of Consumer

$579 \quad$ Studies, 37(5), pp. 522-529. doi: 10.1111/ijcs.12017.

580 Zhang, P. et al. (2002) 'Influence of clothing material properties on rectal temperature in

581 different environments', International Journal of Clothing Science and Technology, 14(5), pp.

582 299-306. doi: 10.1108/09556220210446112.

583 Zhang, Z. et al. (2002) 'Casual wear product attributes: A Chinese consumers' perspective',

584 Journal of Fashion Marketing and Management, 6(1), pp. 53-62. doi:

$585 \quad 10.1108 / 13612020210422464$. 
Fig 1.

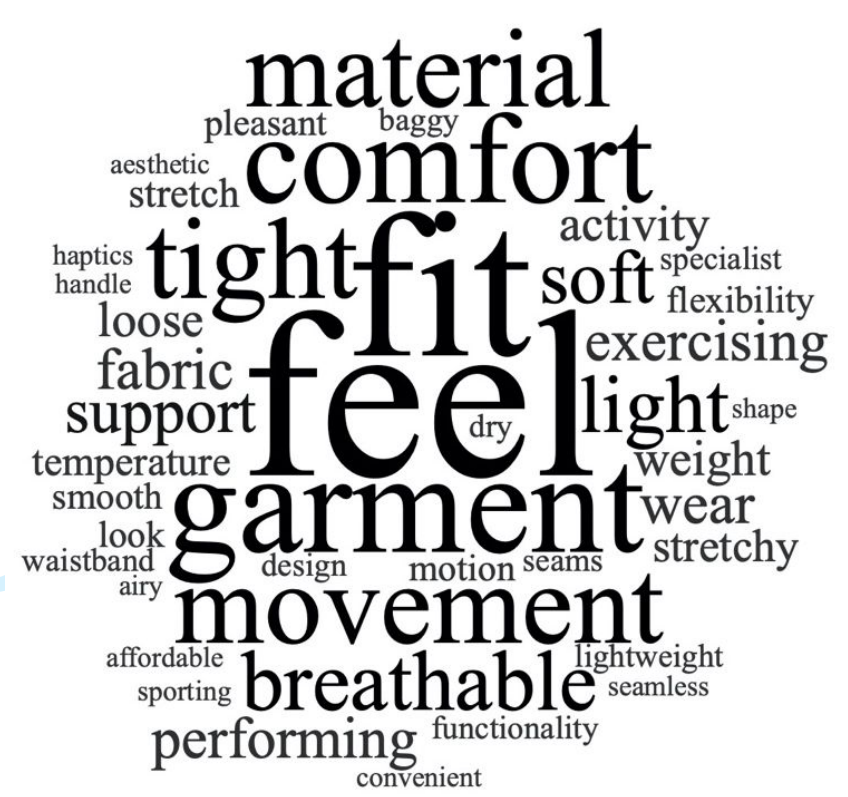

Figure 1: Word cloud representing the description of comfort by the participants ("How would you describe comfort in sports garments for you?").

Fig 2.

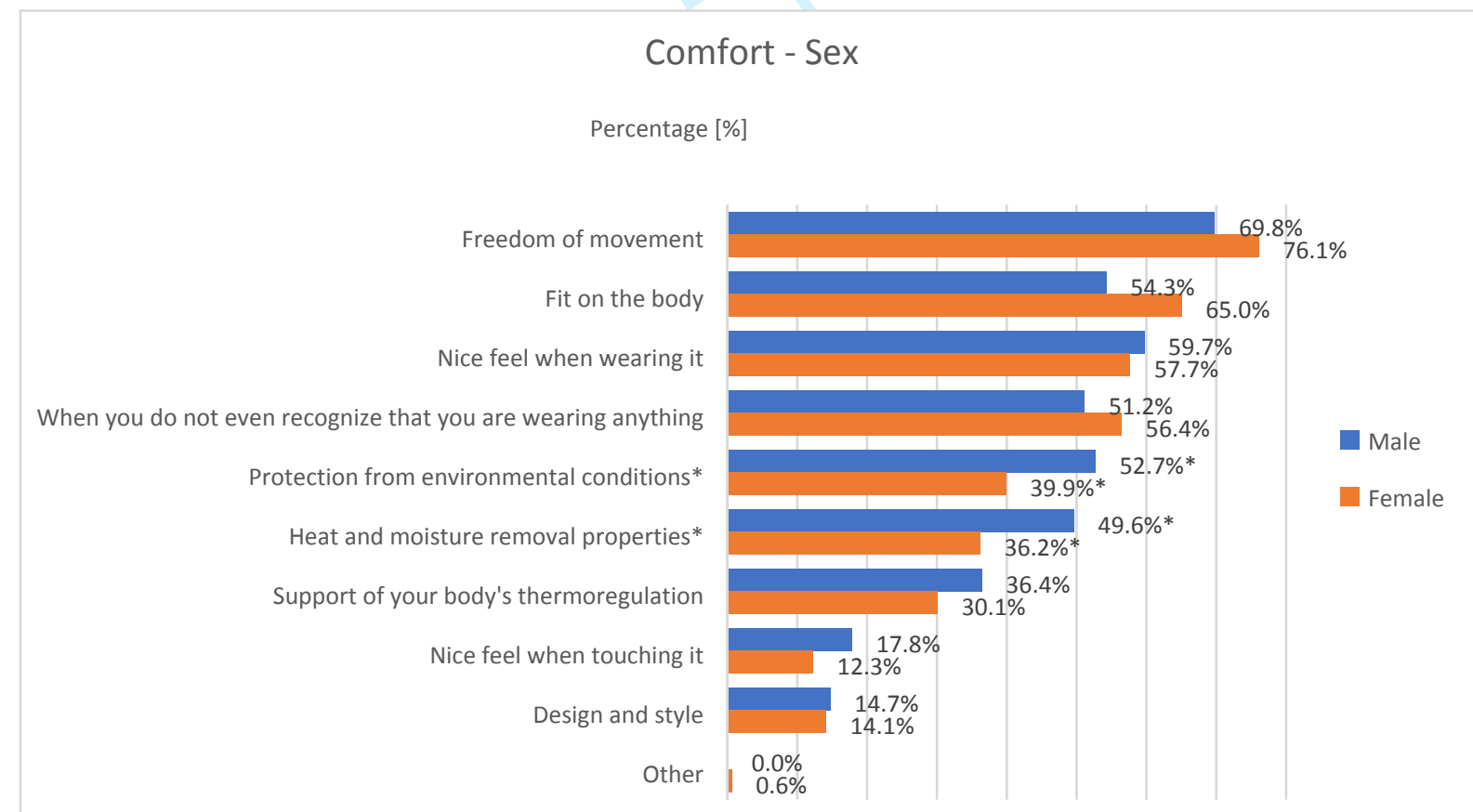

Figure 2: "What is comfort in sports garments for you?" Comparison of comfort descriptors broken down by sex. * indicates a significant difference between the two groups. 
Fig 3.

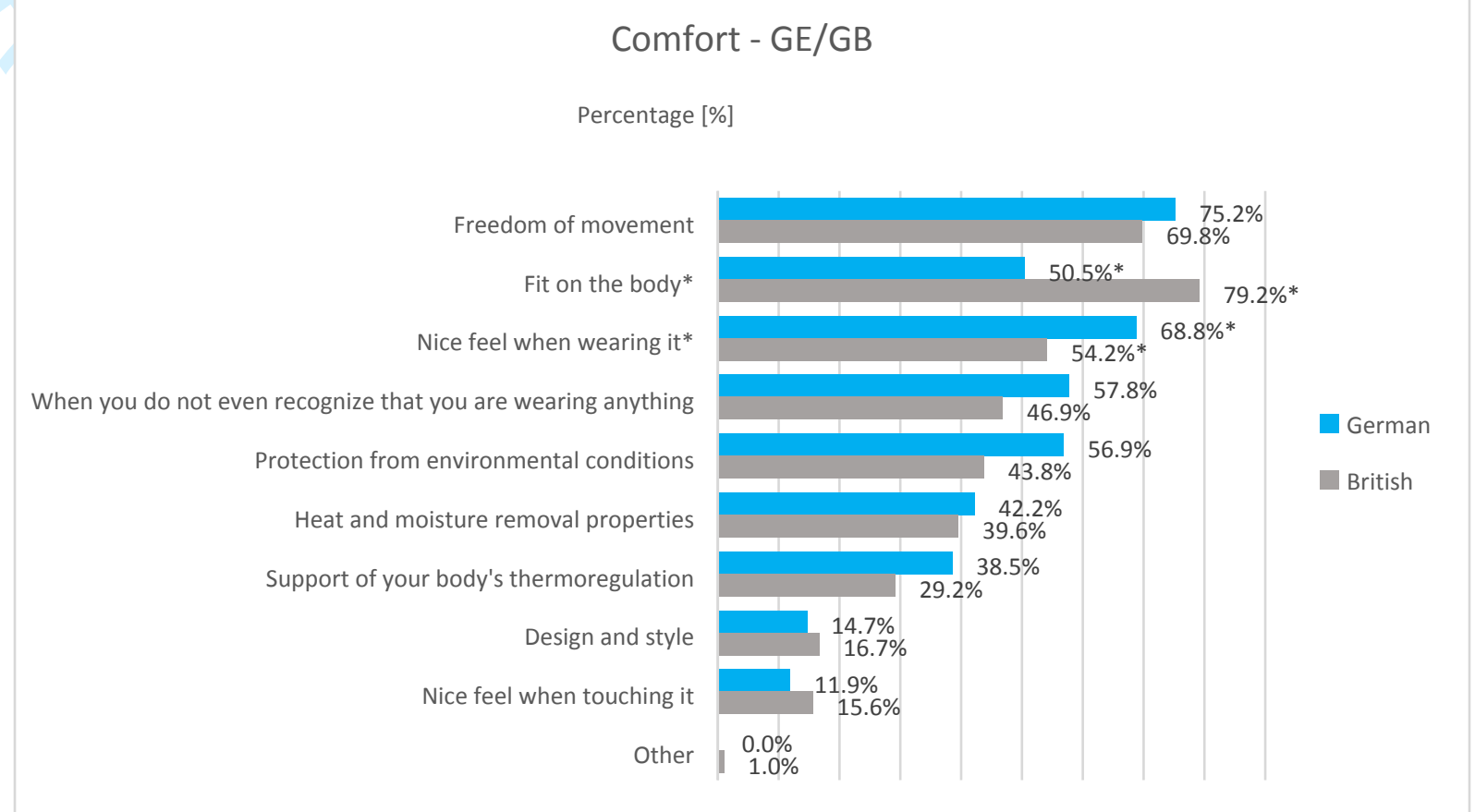

Figure 3: "What is comfort in sports garments for you?" Comparison of comfort descriptors broken down by nationality (German and British) ( $\mathrm{n}=205) . *$ indicates a significant difference between the two groups.

Fig 4.

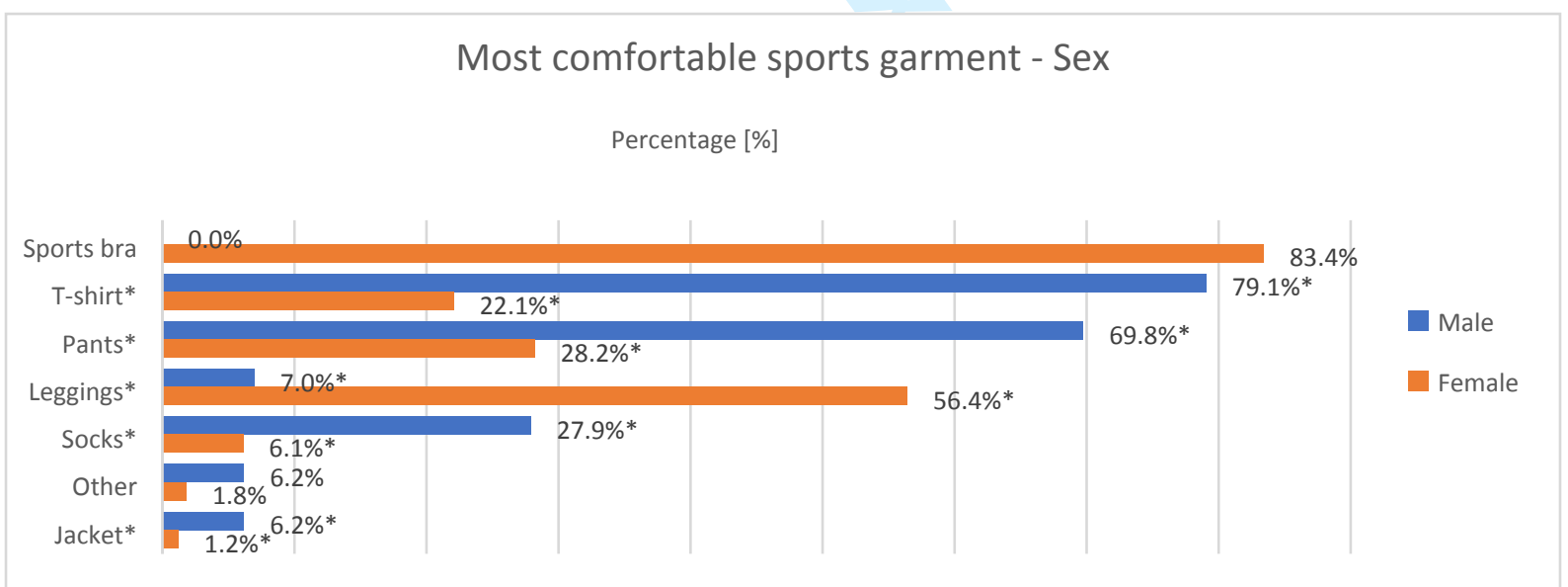

Figure 4: "When undertaking physical activity choose up to two garment-types which are most important to be most comfortable." Most comfortable sports garment type broken down by sex. * indicates a significant difference between the two groups. 
Fig 5.

a)

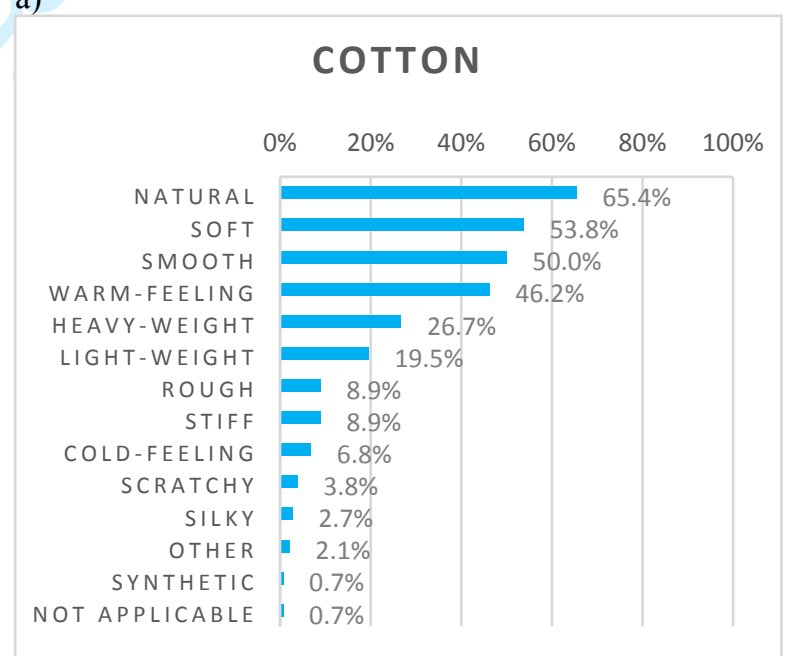

c)

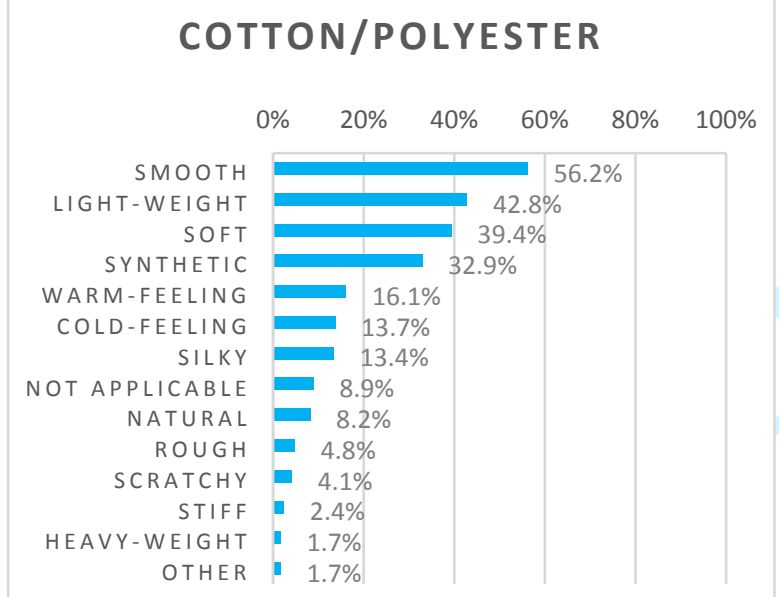

b)

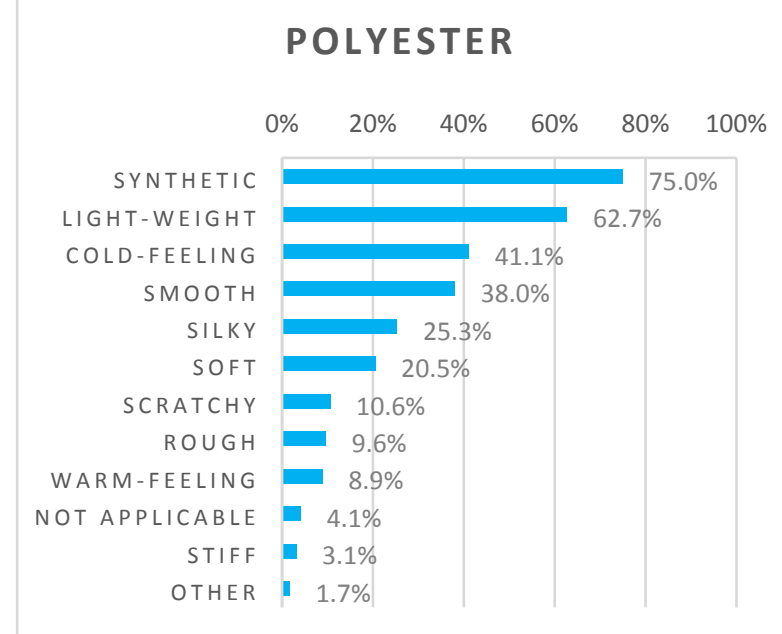

d)

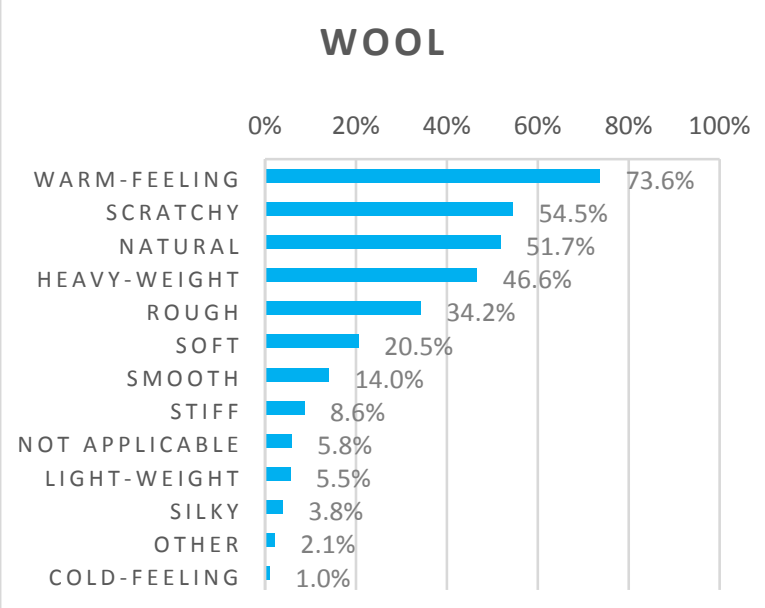

Figure 5: "What characteristic attributes apply when thinking about the feel of a t-shirt made out of cotton, polyester, cotton/polyester blend and wool" Consumer attitude regarding different fibre types (a) cotton, b) polyester, c) cotton/polyester blend, d) wool).

Fig 6.
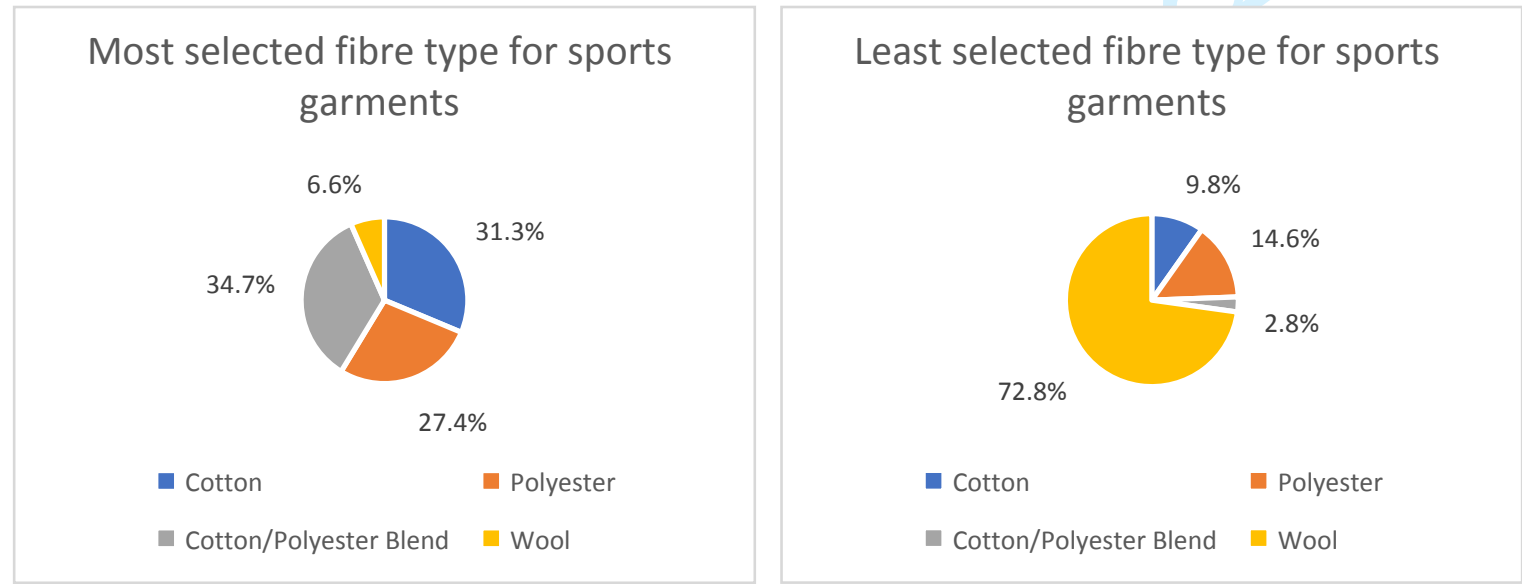

Figure 6: "Please sort the fibre types from most favourite (1) to least favourite (4) one in your sports garments." Comparison of most (left) and least (right) favourite fibre type in sports garments. 
Fig 7.
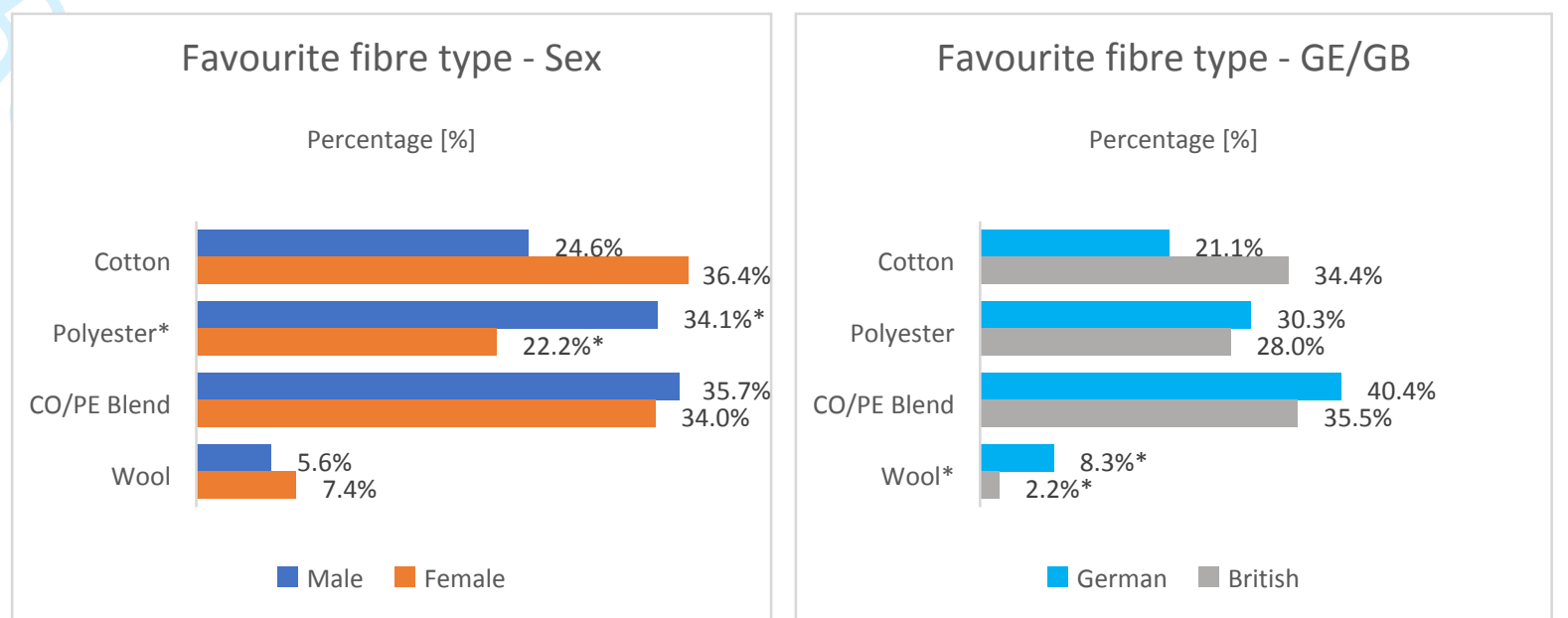

Figure 7: "Please sort the fibre types from most favourite (1) to least favourite (4) one in your sports garments." Favourite fibre type broken down by sex (left) and nationality (right). * indicates a significant difference between the two groups. 


\section{Table}

\section{Table I:}

Table I: Respondent profile. Nationality “other” consists of respondents within Europe (e.g., Spanish, Italian, Dutch, etc.) and from continents other than Europe (e.g., Asia, Africa, North and South America).

\begin{tabular}{|c|c|c|c|}
\hline & 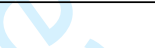 & Male & Female \\
\hline Sex & 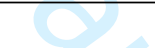 & $44.2 \%$ & $55.8 \%$ \\
\hline \multicolumn{4}{|c|}{ Age [years] } \\
\hline & $18-25$ & $25.6 \%$ & $37.4 \%$ \\
\hline & $26-35$ & $53.5 \%$ & $35.6 \%$ \\
\hline & $36-45$ & $7.0 \%$ & $12.9 \%$ \\
\hline & $46-55$ & $10.1 \%$ & $8.0 \%$ \\
\hline & above 55 & $3.9 \%$ & $6.1 \%$ \\
\hline \multicolumn{4}{|c|}{ Weekly hours [h] of sports } \\
\hline & $0-1$ & $0.8 \%$ & $0.6 \%$ \\
\hline & $1-2$ & $5.4 \%$ & $9.8 \%$ \\
\hline & $2-5$ & $43.4 \%$ & $45.4 \%$ \\
\hline & $5-10$ & $34.9 \%$ & $31.3 \%$ \\
\hline & $10+$ & $12.4 \%$ & $5.5 \%$ \\
\hline & No sports & $3.1 \%$ & $7.4 \%$ \\
\hline \multicolumn{4}{|c|}{ Nationality } \\
\hline & German & $41.1 \%$ & $34.4 \%$ \\
\hline & British & $28.7 \%$ & $36.2 \%$ \\
\hline & Other & $30.2 \%$ & $29.4 \%$ \\
\hline
\end{tabular}




\section{Loughborough University}

\section{Clothing Comfort in Sports Garments}

Page 1: Your opinion is very valuable!

When purchasing a sports garment, consumers are very limited on time for deciding whether they like the garment's textile. The purpose of this study is to find out which clothing and comfort attributes influence people when purchasing sports garments and to identify the consumer attitude in regards to specific materials. Understanding and satisfying consumer needs are crucial for the growth of clothing and textile industry. One of the most important issues is to understand what the concept of clothing comfort means and how it can be engineered into fabrics and sports garments.

This research is part of a PhD project investigating the haptics of sports textiles. We would like to ask you to give us your personal and honest opinion. The survey will take about 10-15 minutes of your time. 


\section{Page 2: Informed consent}

The purpose and details of this study are clear to me. I understand that this study is designed to further scientific knowledge and that all procedures have been approved by the Loughborough University Ethics Approvals (Human Participants) Sub-Committee.

I understand that all the personal information I provide will be processed in accordance with data protection legislation on the public task basis and will be treated in strict confidence.

I understand that information I provide will be used for publications, reports, and research outputs.

1. I voluntarily take part in this study. * Required

C Yes, I agree. 


\section{Page 3: Exercising and sports}

2. Do you undertake physical activity on a regular basis?

fr yes

r no

2.a. What kind of physical activity do you undertake regurarly?

$\lceil$ Team sports (Basketball, Football, etc.)

$\Gamma$ Running

$\Gamma$ Cycling

$\Gamma$ Water sports (Swimming, Surfing, etc.)

$\Gamma$ Racket sport (Tennis, Squash, etc.)

$\Gamma$ Gym

$\Gamma$ Athletics

$\Gamma$ Outdoor sports (Hiking, Skiing, etc.)

$\Gamma$ Yoga/Pilates

$\Gamma$ Other

2.a.i. If you selected Other, please specify:

2.b. How many hours per week do you undertake physical activity?
0-1
c $1-2$
c $2-5$
f) $5-10$
r $10+$

3. Do you wear sports garments?

of yes

r no 


\section{Page 4: Purchase behaviour}

4. Where do you usually purchase sports garments?
or Online
S Store
Both, online and store

4.a. Which type of online shop or actual store do you usually purchase sports garments?

$\Gamma$ Specialist (Intersport, Sports Direct, Decathlon, JD sports, etc.)

$\sqcap$ Non-specialist (H\&M, Zara, C\&A, etc.)

4.b. Why do you purchase sports garments in a store?

$\Gamma$ Consulting service

$\Gamma$ Feel of the garment

$\Gamma$ Sizing/fit of the garment

$\lceil$ Support of local business

$\Gamma$ Look/appearance of the garment

$\lceil$ Personal experience

$\lceil$ Pleasant pastime

$\Gamma$ Promotions (Sales)

$\Gamma$ Impulse purchase

$\Gamma$ Other

4.b.i. If you selected Other, please specify:

4.c. Why do you purchase sports garments online?

$\llbracket$ Less time consuming

$\Gamma$ Greater range of sizes

$\Gamma$ Greater range of designs

$\lceil$ Pleasant pastime

$\Gamma$ Convenience

$\Gamma$ Brand is only available online

$\Gamma$ No influence of other people's opinion

$\Gamma$ Advertisement (social media, etc.)

$\ulcorner$ Cheaper price

$\Gamma$ Other

4.c.i. If you selected Other, please specify: 
5. Have you purchased any sports garments in the last 6 months before the COVID-19 lockdown period started?

ryes

c no

5.a. Where did you purchase the garment(s)?

c Online

$r$ Store

c Both, online and store

6. I am using sports garments...

$\ulcorner\quad$... for sports or fitness purposes

$\Gamma \quad$... for casual wear

$\Gamma \ldots$... to look sportive

$\ulcorner\ldots$... to follow a trend

$\ulcorner$ Other

6.a. The sports or fitness purpose I use the garment for is...

r... only the specific sports the garment was designed for

r... also sports other than the one for which the garment was designed for

6.b. If you selected Other, please specify:

7. What are the three most important attributes you look for when purchasing sports garments?

Please select exactly 3 answer(s).

$\ulcorner$ Comfort

$\Gamma$ Fit (tightlloose)

$\ulcorner$ Style

$\ulcorner$ Colour

$\ulcorner$ Brand name

$\ulcorner$ Durability

$\ulcorner$ Functionality (moisture management, breathability)

$\ulcorner$ Price

$\Gamma$ Ease of care

$\Gamma$ Country of manufacturing (made in ...)

$\ulcorner$ Type of material

$\Gamma$ Environmental impact

$\ulcorner$ Discounts

$\Gamma$ Improvement in personal performance

$\Gamma$ Other 
7.a. How would you describe comfort in sports garments for you?

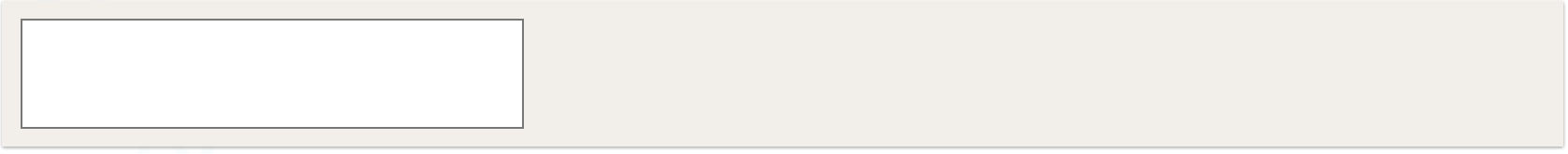

7.b. What kind of material would you prefer in sports garments?

(5) Natural

Synthetic

7.c. If you selected Other, please specify: 


\section{Page 5: Feel of sports shirts}

8. What characteristic attributes apply when thinking about the feel of a t-shirt made out of...

\begin{tabular}{|c|c|c|c|c|c|c|c|c|c|c|c|c|c|c|c|}
\hline & smooth & rough & $\begin{array}{l}\text { warm- } \\
\text { feeling }\end{array}$ & $\begin{array}{l}\text { cold- } \\
\text { feeling }\end{array}$ & scratchy & soft & synthetic & natural & $\begin{array}{l}\text { heavy- } \\
\text { weight }\end{array}$ & $\begin{array}{l}\text { light- } \\
\text { weight }\end{array}$ & stiff & silky & $\begin{array}{c}\text { not } \\
\text { applicable }\end{array}$ & Other & If you \\
\hline Cotton & $\Gamma$ & $\Gamma$ & $\Gamma$ & $\Gamma$ & $\Gamma$ & $\Gamma$ & $\Gamma$ & $\Gamma$ & $\Gamma$ & $\Gamma$ & $\Gamma$ & $\Gamma$ & $\Gamma$ & $\Gamma$ & \\
\hline $\begin{array}{l}\text { Cotton/Polyester } \\
\text { Blend }\end{array}$ & $\Gamma$ & $\Gamma$ & $\Gamma$ & $\Gamma$ & $\Gamma$ & $\Gamma$ & $\Gamma$ & $\Gamma$ & $\Gamma$ & $\Gamma$ & $\Gamma$ & $\Gamma$ & $\Gamma$ & $\Gamma$ & \\
\hline
\end{tabular}

\section{Please sort the fibre types from most favourite (1) to least favourite (4) one in your sports garments}

Please don't select more than 1 answer(s) per row.

Please don't select more than 1 answer(s) in any single column.

\begin{tabular}{|c|c|c|c|c|}
\hline & 1 & 2 & 3 & 4 \\
\hline Cotton & $\Gamma$ & $\Gamma$ & $\Gamma$ & $\Gamma$ \\
\hline Polyester & $\Gamma$ & $\Gamma$ & $\Gamma$ & $\Gamma$ \\
\hline Cotton/Polyester Blend & $\Gamma$ & $\Gamma$ & $\Gamma$ & $\Gamma$ \\
\hline Wool & $\Gamma$ & $\Gamma$ & $\Gamma$ & $\Gamma$ \\
\hline
\end{tabular}

10. When undertaking physical activity choose up to two garment-types which are most important to be most comfortable

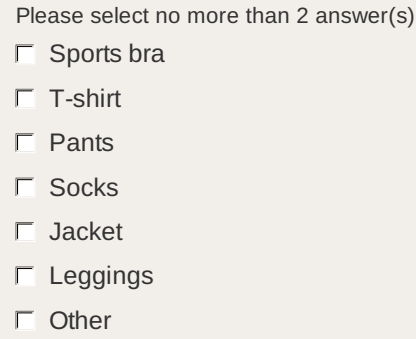

10.a. If you selected Other, please specify:

11. What is comfort in sports garments for you?

$\Gamma$ When you do not even recognize that you are wearing anything

$\Gamma$ Heat and moisture removal properties

$\ulcorner$ Nice feel when touching it

$\Gamma$ Nice feel when wearing it

$\Gamma$ Design and style

$\Gamma$ Protection from environmental conditions (keeping you warm, water repellent, etc.)

$\lceil$ Support of your body's thermoregulation 


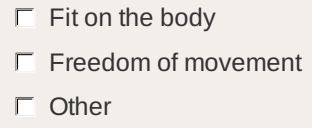

11.a. If you selected Other, please specify: 


\section{Page 6: Your personalized sports t-shirt}

12. Imagine you could design your own individual running-shirt from scratch. Pick the fibre type for the production of your running t-shirt for summer.

13. What attributes are important in your running t-shirt for summer?
$\Gamma$ Roughness
$\Gamma$ Natural touch
$\Gamma$ Breathability
$\Gamma$ Warmness to the touch
$\Gamma$ Stretchability
$\Gamma$ Smoothness
$\Gamma$ Synthetic touch
$\lceil$ Thickness
$\Gamma$ Coolness to the touch
$\llbracket$ Lightweight
$\Gamma$ Softness
$\Gamma$ Flexibility
$\Gamma$ Other

13.a. If you selected Other, please specify:

14. What attributes do not matter in your running t-shirt for summer?
$\lceil$ Roughness
$\lceil$ Natural touch
$\Gamma$ Breathability
$\Gamma$ Warmness to the touch
$\Gamma$ Stretchability
$\Gamma$ Smoothness
$\Gamma$ Synthetic touch
$\Gamma$ Thickness
$\Gamma$ Coolness to the touch
$\Gamma$ Lightweight
$\Gamma$ Softness
$\Gamma$ Flexibility
$\Gamma$ Other

14.a. If you selected Other, please specify: 
Page 7: Anthropometric data

15. Are you?

f Male

F Female

16. What is your age?
(f $18-25$
c 26-35
c $36-45$
of $46-55$
r above 55

17. What is your continent of origin?
f Europe
c North America
c. South America
f Oceania
c Africa
C Asia

18. What is your nationality? 